\title{
Wettability alteration of oil-wet limestone using surfactant-nanoparticle formulation
}

Lezorgia N. Nwidee ${ }^{\mathrm{a}}$, Maxim Lebedev ${ }^{\mathrm{b}}$, Ahmed Barifcani ${ }^{\mathrm{a}}$, Mohammad Sarmadivaleh ${ }^{\mathrm{a}}$, Stefan Iglauer ${ }^{\mathrm{a}}$

${ }^{a}$ Department of Petroleum Engineering, Curtin University, 26 Dick Perry Avenue, 6151 Kensington, Perth, Western Australia

${ }^{b}$ Department of Exploration Geophysics, Curtin University, 26 Dick Perry Avenue, 6151 Kensington, Perth, Western Australia

\begin{abstract}
Wettability remains a prime factor that controls fluid displacement at pore-scale with substantial impact on multi-phase flow in the subsurface. As the rock surface becomes hydrophobic any oleic phase present is tightly stored in the rock matrix and be produced (hydrocarbon recovery) or cleaned up (soil-decontamination) by standard waterflooding methods. Although surface active agents such as surfactants have been used for several decades for changing the wetting states of such rocks, an aspect that has been barely premeditated is the simultaneous blends of surfactants and nanoparticles. This study thus systematically reports the behaviour of surfactants augmented nanoparticles on wettability alteration. Contact angle, spontaneous imbibition, and mechanistic approaches were adopted to assess the technical feasibility of the newly formulated wetting agents, tested over wide-ranging conditions to ascertain efficient wetting propensities. The contact angle measurement is in good agreement with the morphological and topographical studies and spontaneous imbibition. The wetting trends for the formulated systems indicate advancing and receding water angles decreased with increase in nanoparticle concentration and temperature, and the spontaneous water imbibition test also showed faster water-imbibing tendencies for nanoparticle-surfactant exposed cores. Thus, the new formulated nanoparticlesurfactant systems were considered suitable for enhancing oil recovery and soil-decontamination, particularly in fractured hydrophobic reservoirs.
\end{abstract}

Keywords: Nanoparticles, Surfactants, Wettability, Limestone, Imbibition, Contact angle. 


\section{Introduction}

Porous rock wetting and imbibition are complex processes which pose a continual challenge in subsurface reservoir practices. Typically, formations exhibit different degrees of wetting tendencies such as water-wet, oil-wet, or intermediate wet (or anything in between). Water-wet formations display a great affinity for water than oil, and oil-wet formations retain the oleic phase much better in the tight pore matrix of the rock. It is, however, a key question how the wetting state of such formations can be rendered more water-wet to facilitate better hydrocarbon recovery [1-4], soil-decontamination, or enhanced carbon geo-sequestration processes [5-8]. Surfactant-flooding has been recognised as an approach that promotes adequate displacement of oil from porous media when used in adequate volumes, especially in depleted formations [9]. Its usage has been widely investigated [10-23] as active agents for reduction of oil-water interfacial tension (IFT) [11], [24-26] and residual oil saturation [10]. Surfactants are also good wettability modifiers for solid-liquid interfaces [15], [27], [28], although, the kinetics, uniformity and wettability alteration efficiency of the surfactants are complex and depend on the properties of the surfactant and the solid surface of the porous medium that the surfactants are in contact with [29, 30]. Surfactants can accumulate in three-dimensional nano and micro structures (micelles, vesicles, liquid crystalline phases) when they reach a sufficient concentration in solution $[31,32]$ but their prime characteristic in enhancing oil recovery (EOR) is the capacity to adsorb on surfaces or interfaces [33-35] even at minimal concentrations. This can lead to surfactant loss due to adsorption on the reservoir rock surface; an effect which needs to be minimized as the efficiency of the EOR process is reduced [22], [24], [36-38].

Recently, nanoparticle - typically stable metal oxides sized between 1-100nm [4], [39-41] have received increased interest as an additive to EOR-surfactant formulations [42, 43] as it 
displays different and better properties in comparison to the bulk material counterparts. Its great chemical stability makes it particularly interesting for formulations of suspensions or emulsions [4, 44]. Ahmadi and Shadizadeh [45] assessed the adsorption behaviour of Zyziphus spina-christi surfactant in the presence of silica nanoparticles on sandstone shale and found that adsorption losses on shale sandstone were better inhibited by hydrophobic silica nanoparticle than hydrophilic silica nanoparticle due to more hydrophobic bonds created between hydrophobic tail of surfactant and hydrophobic part of nano silica particles. Lan et al. [46] investigated the synergistic effects of silica nanoparticles and cationic surfactants on the emulsion stability on basis of concentration and dispersion ph. It was found that the interfacial adsorption of the silica nanoparticle increased with increasing cationic surfactant concentration thus an indication of a clear synergistic effect on interfacial tension (IFT) reduction, such effect in IFT reduction was attributed to emulsion stability.

Despite the relevance of studies on adsorption behaviour and IFT at the liquid-liquid interface [37, 47], the mechanisms and interaction between surfactant augmented nanoparticles on the solid-liquid interface is not fully understood and remains a challenge especially for contact lines moving in nanoscale systems. Such effect has barely been reported in in oil wet limestone reservoir, as such an understanding of the wetting proficiency in this formation is imperative as fluid displacement at pore scale is greatly dependent on the reservoir wettability. This rock type is of interest as its naturally fractured and hydrophobic nature makes it difficult for water to imbibe into its matrix owing to negative capillary pressure; capillary pressure is thus defined as the pressure variation between two fluid phases that are in contact. Such contacts between immiscible fluids in the rock pore spaces leads to pressure discontinuity across the 
interfaces and it is dependent on IFT, pore size, and wetting angle and thus considered [93, 94]. The pressure difference between the wetting and non-wetting fluid phase is established thus:

$$
\mathrm{P}_{\mathrm{c}}=\mathrm{P}_{\mathrm{n}}-\mathrm{P}_{\mathrm{w}}
$$

Where $P_{c}$ - capillary pressure; $P_{n}$ - non-wetting pressure; $P_{w}$ - wetting pressure

Typically, oil recoveries from such fractured reservoirs are usually very poor with average recovery factor of about 10-35\% [25], [36], [44], however, if such oil-wet surface can be rendered water-wet, spontaneous imbibition of water into the matrix pores (where most of the oil resides) massively increases recovery factors to $50-70 \%$ [48-51]. However, water wet media exhibit increased snap-off events which lead to increased residual oil saturations after water breakthrough and subsequent poor oil recovery [86]. The relevance of wetting and its effect on rock-fluid properties cannot be over emphasize, aside from its importance in subsurface reservoir evaluation, it is of great relevance for characterization and selection of materials. Hence, we tested the wetting propensity of new nanoparticle-surfactant formulations in strongly hydrophobic limestone, which can enhance the possibilities for significant additional oil recoveries from fractured reservoirs. Two different surfactants (cationic and non-anionic) and nanoparticles (zirconium oxide and nickel oxide) was systematically evaluated as a function of surfactant type and concentrations, nanoparticle-surfactant type and concentrations, temperature, and imbibition. 


\section{Experimental Procedure}

\subsection{Materials}

Triton X-100 (TX-100 Sigma Aldrich - purity 99.0 mol. \%; molecular weight - 625 $\mathrm{g} / \mathrm{mol}$; critical micelle concentration $-0.2-0.9 \mathrm{mM}$ ) and cetyltrimethylammonium bromide (C 16 TAB Sigma Aldrich - Purity 99.0 mol. \%; molecular weight - 364.45 g/mol; critical micelle concentration - $0.92 \mathrm{mM})$ were used as surfactants (Fig. 1). Dodecyltriethoxysilane $\left(\mathrm{C}_{18} \mathrm{H}_{40} \mathrm{O}_{3} \mathrm{Si}\right.$; Purity 99.0 mol. \%; Molecular weight $332.59 \mathrm{~g} / \mathrm{mol} ; 265.25{ }^{\circ} \mathrm{C}$ ) from Sigma Aldrich (Fig.1) was used as a wettability modifier, see below; and Zirconium (IV) oxide $\left(\mathrm{ZrO}_{2}\right)$ from Sigma Aldrich (purity: 99.5 wt. \%) and Nickel (II) oxide (NiO) (purity 99.5 wt. \%) were used as nanoparticles

(Table 1). Iceland spar calcite crystal (from Ward Science) was used as a representative of limestone formations. Toluene (from Sigma Aldrich; purity 99.9 mol. \%) was used as model oil. Ultrapure de-ionized water (Purity 99.0 mol. \%; David Gray) were used as dispersing agents for all the tests. 
a)<smiles>CCO[Si](OCC)(OCC)C(CC)CC</smiles>

b)<smiles>CCCC(C)(C)[N+](C)(C)Br</smiles>

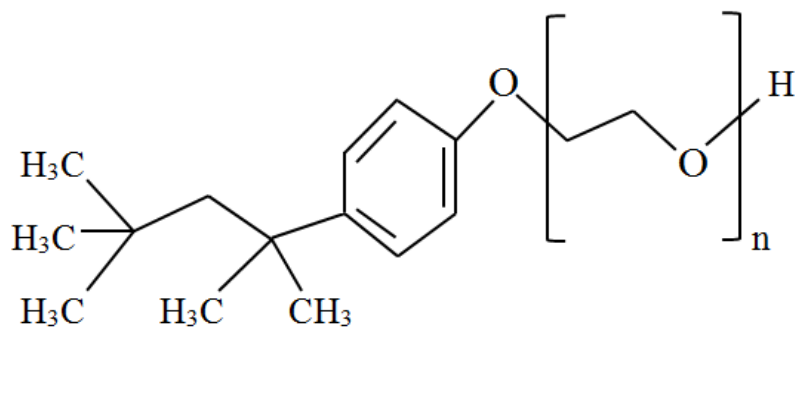

Fig. 1. Structure of silane: a) Dodecyltriethoxysilane; and surfactants: b) Cetyltrimethylammonium bromide, c) Triton X-100.

\subsection{Fluids Formulation, Surface Cleaning, and Modification}

Surfactant $\left(\mathrm{C}_{16} \mathrm{TAB}, \mathrm{TX}-100: 0.05-0.5\right.$ wt. \%) solutions were prepared with a 220V/50HZ magnetic stirrer and deionised water as a dispersing agent. Nanoparticle-surfactants $\left(\mathrm{ZrO}_{2} / \mathrm{C}_{16} \mathrm{TAB} ; \mathrm{ZrO}_{2} / \mathrm{TX}-100, \mathrm{NiO} / \mathrm{C}_{16} \mathrm{TAB} ; \mathrm{NiO} / \mathrm{TX}-100\right)$ were formulated by adding fixed surfactant concentration $\left(\mathrm{C}_{16} \mathrm{TAB}\right.$ and $\left.\mathrm{TX}-100-0.5 \mathrm{wt} . \%\right)$ to the nanosuspensions of varied concentrations $\left(\mathrm{ZrO}_{2}\right.$ and $\mathrm{NiO}-0.004-0.05$ wt. \%). The mixture was stirred with a magnetic stirrer (60 minutes) and sonicated with a 300VT ultrasonic homogenizer (60 minutes) to create homogeneous fluids.

Calcite crystals were cleaned with acetone, methanol and deionised water then dried in air plasma for 15 minutes [52-54] to remove any residual organic contaminants. The cleaned 
samples were modified to oil-wet by ageing in silane (dodecyltriethoxysilane) for 12 hours at $90^{\circ} \mathrm{C}$. Samples were then separated from the silane phase, cleaned with methanol and deionised water then dried in the air [3], [4], [40] to remove excess silane from the surface of the rock. The Indiana limestone core (calcium carbonate - 100\% - Table 2) has an average length $5.8 \mathrm{~cm}$ and diameter $2.2 \mathrm{~cm}$, average porosity of $19.5 \%$ and a wide-range of permeability (Table 3 ). The porosity and permeability were measured with an AP-608 automated porosimeter-permeameter (accuracy $\pm 0.1 \%$ ). All cores were cleaned via soxhlet extraction using toluene and methanol for removal of organic contaminants or absorbed material from the core plugs, then dried at $60^{\circ} \mathrm{C}$ for $24 \mathrm{hrs}$ to constant weight. Dried cores were aged in silane at $90^{\circ} \mathrm{C}$ under vacuum for 48 hours [5557], subsequently, the cores were separated from the silane phase, cleaned with toluene, methanol, and deionised water, and dried at $60^{\circ} \mathrm{C}$.

\subsection{Surface Characterization}

The surface morphology of the modified and unmodified substrates was characterized via scanning electron microscopy (SEM- a Zeiss Neon 40EsB FIBSEM). The topography of the calcites was also examined via atomic-force microscopy (AFM- a Dual Scope TM C-26 Scanning probe and optical microscope with DME software- DSE 95-200).

\subsection{Wettability Determination}

Contact angle $(\theta)$ was used as the deterministic tool for wettability assessments. Tilted plate technique [58] and microscopic camera (Basler scA 640-70 fm, pixel size $=7.4 \mu \mathrm{m}$; frame 
rate $=71 \mathrm{fps}$; Fujinon CCTV lens: HF35HA-1B; 1:1.6/35 mm) were used for water contact angle measurement in toluene. Experiments were conducted over a range of temperatures $\left(22-70^{\circ} \mathrm{C} \pm\right.$ $1^{\circ} \mathrm{C}$ ) and fluid densities $(\mathrm{g} / \mathrm{ml})$ were also measured (Toluene-0.848; $\mathrm{C}_{16} \mathrm{TAB}-0.962$; TX-1000.951; $\left.\mathrm{ZrO}_{2} / \mathrm{C}_{16} \mathrm{TAB}-0.977 ; \quad \mathrm{ZrO}_{2} / \mathrm{TX}-100-0.965 ; \quad \mathrm{NiO} / \mathrm{C}_{16} \mathrm{TAB}-0.947 ; \quad \mathrm{NiO} / \mathrm{TX}-100-0.998\right)$. Prior to the receding $\left(\theta_{\mathrm{r}}\right)$ and advancing contact $\left(\theta_{\mathrm{a}}\right)$ angle measurements, oil-wet calcite samples were exposed to the formulated fluids (Surfactants: $\mathrm{C}_{16} \mathrm{TAB}$ and TX-100; nanoparticle surfactants systems: $\mathrm{ZrO}_{2} / \mathrm{C}_{16} \mathrm{TAB}, \mathrm{ZrO}_{2} / \mathrm{TX}-100, \mathrm{NiO} / \mathrm{C}_{16} \mathrm{TAB}$ and $\mathrm{NiO} / \mathrm{TX}-100$ ) for a fixed period of one hour at ambient conditions. Subsequently, the calcite substrates were dried in air and a water droplet was dispensed on the modified calcite substrate which was observed microscopically. Thereafter, the receding and advancing water contact angles were measured, the contact angle of the drop was analysed using Image $\mathrm{J}$ software and the standard deviation of $\pm 3^{\circ}$ based on replicate measurements. With respect to spontaneous imbibition (SI), wettability was assessed to test the water imbibing potentials of limestone cores placed in water under balance. The core plugs were aged in the nanofluids at $60^{\circ} \mathrm{C}$ temperature for 48 hours, then the cores were removed from the formulations and dried at $50^{\circ} \mathrm{C}$ for 24 hours for imbibition testing. The weight gained is recorded as a function of time until equilibrium is attained, and quantified by an estimation of the ratio of the weight of water imbibed at a given time and at equilibrium [59].

Table 1. Properties of nanoparticles used.

\begin{tabular}{llllll}
\hline Nanoparticles & $\begin{array}{l}\text { Concentratio } \\
\mathrm{n}(\text { Wt. \%) }\end{array}$ & $\begin{array}{l}\text { Chemical } \\
\text { formula }\end{array}$ & $\begin{array}{l}\text { Molecular } \\
\text { Weight } \\
(\mathrm{g} / \mathrm{mol})\end{array}$ & Form & $\begin{array}{l}\text { Particle } \\
\text { Size } \\
(\mathrm{nm})(\mathrm{TEM})\end{array}$ \\
\hline Zirconium Oxide & $(0.004-0.05)$ & $\mathrm{ZrO}_{2}$ & 123.22 & Nanopowder & $<50$ \\
Nickel Oxide & $(0.004-0.05)$ & $\mathrm{NiO}$ & 74.69 & Nanopowder & $<50$ \\
\hline
\end{tabular}


Table 2. Rock composition

\begin{tabular}{lccc}
\hline Element & Symbol & Atomic concentration $(\%)$ & Weight concentration $(\%)$ \\
\hline Calcium & $\mathrm{Ca}$ & 8.28 & 19.63 \\
Carbon & $\mathrm{C}$ & 27.07 & 19.22 \\
Oxygen & $\mathrm{O}$ & 64.64 & 61.15 \\
\hline
\end{tabular}

Table 3. Core properties.

\begin{tabular}{lccc}
\hline Cores & $\begin{array}{c}\text { Porosity } \\
(\%)\end{array}$ & $\begin{array}{c}\text { Permeability } \\
\left(\mathrm{K}_{\text {air }}-\mathrm{mD}\right)\end{array}$ & $\begin{array}{c}\text { Permeability } \\
(\text { K-Klink-mD })\end{array}$ \\
\hline Unmodified & 20 & 370 & 310 \\
& & & \\
$\mathrm{C}_{16}$ TAB-modified & 19 & 318 & 264 \\
NiOC $_{16}$ TAB-modified & 20 & 262 & 214 \\
$\mathrm{ZrO}_{2} \mathrm{C}_{16}$ TAB- modified & 19 & 218 & 175 \\
\hline
\end{tabular}

\section{RESULTS AND DISCUSSION}

Improving the wetting and subsequent recovery potentials in limestone formation which is typically intermediate to oil-wet is an essential approach for facilitating fluid displacement at pore-scale. As such wettability was evaluated for both nano-modified and unmodified substrates through morphological and topographical assessment, contact angle $(\theta)$ measurement and spontaneous imbibition (SI), which are the globally accepted approach for quantifying reservoir wettability. Firstly, surfactants wetting proficiency as a function of concentration on oil-wet rock in the absence of nanoparticle, then the nanoparticle-surfactant was tested as a function of nanoparticle concentration and temperature for the preferential selectivity of efficient concentration and suspension type. Then only efficient suspension type and the concentrations thereof were assessed via spontaneous imbibition. 


\subsection{Surface morphological evaluation}

The morphological layered structure of the nanoparticle-surfactant on the solid-liquid interface was examined via SEM. Fig. 2 (a-c) shows the SEM images of the pure calcite and the nanoparticles coated calcites at the micrometre scale. Similar structural morphologies are observed in Fig. 2(d-g) which represents the nanoparticle-surfactant coated substrates. $\mathrm{ZrO}_{2}$ surfactant blends (Fig.2f, g) showed more regular particle shape and uniform spreading than $\mathrm{NiO}$ (Fig. 2d, e). The SEM images depict adsorption of the nanoparticle-surfactants on the surface of the calcite, consistent with previous reports [3], [4], [60-62]. The adsorption behaviour on the surface of the rock facilitated the wettability change as observed via contact angle measurements for all systems tested (Fig. 4-7).

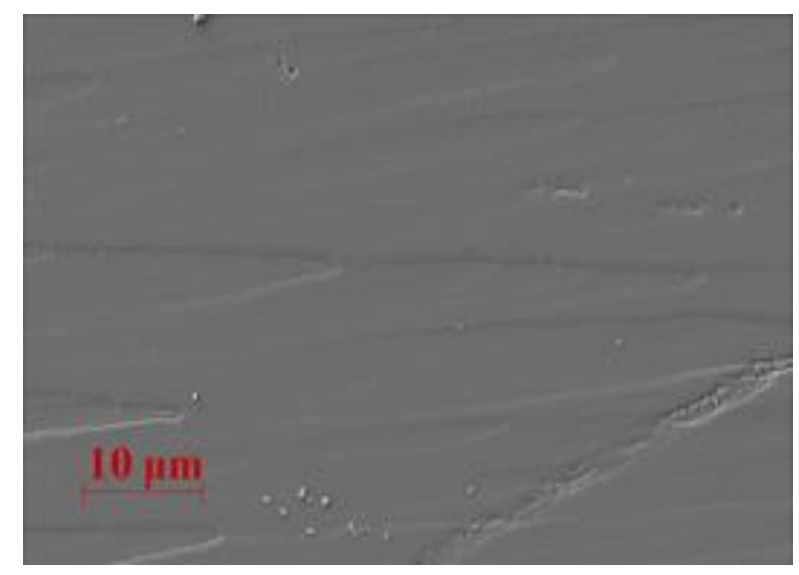

a) 


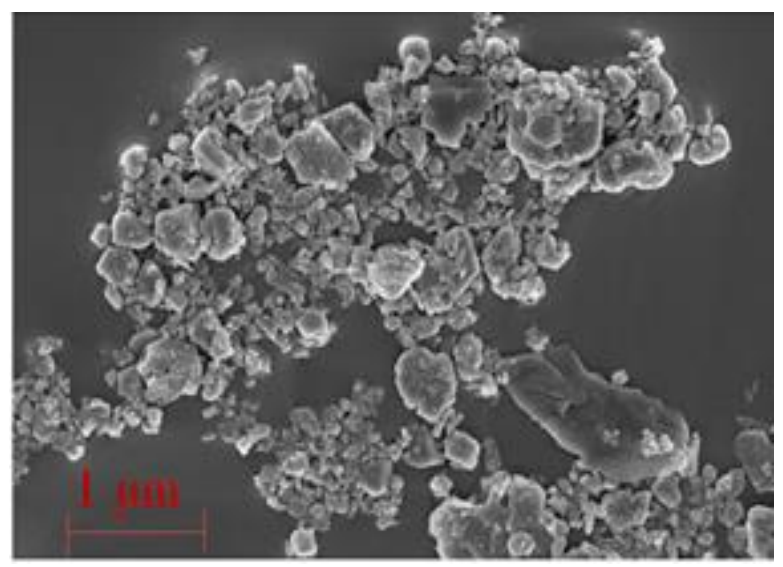

b)

c)

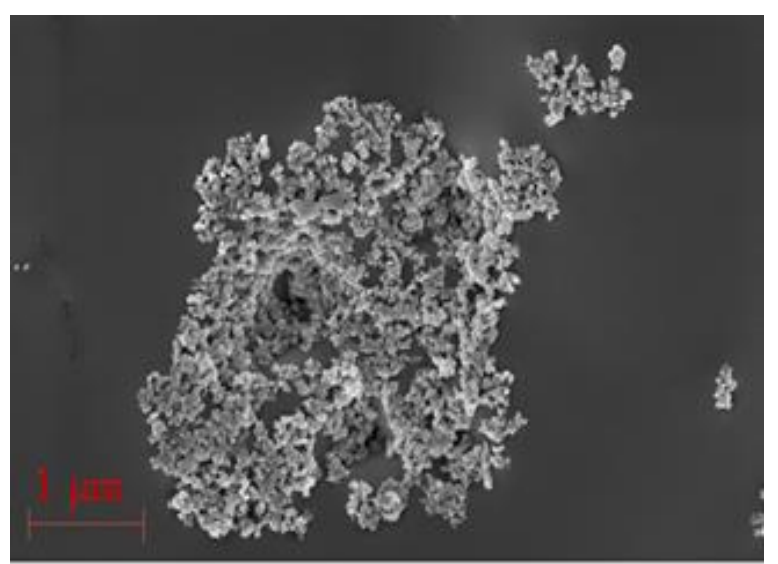




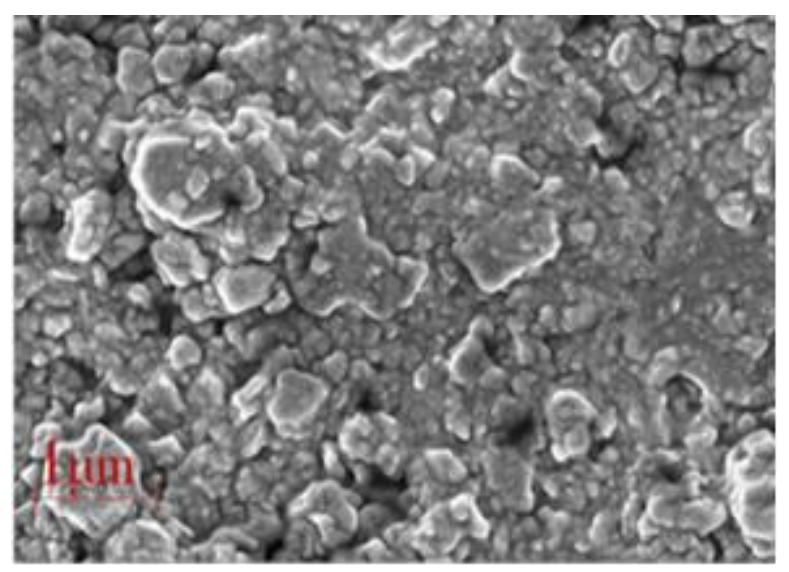

d)

e)

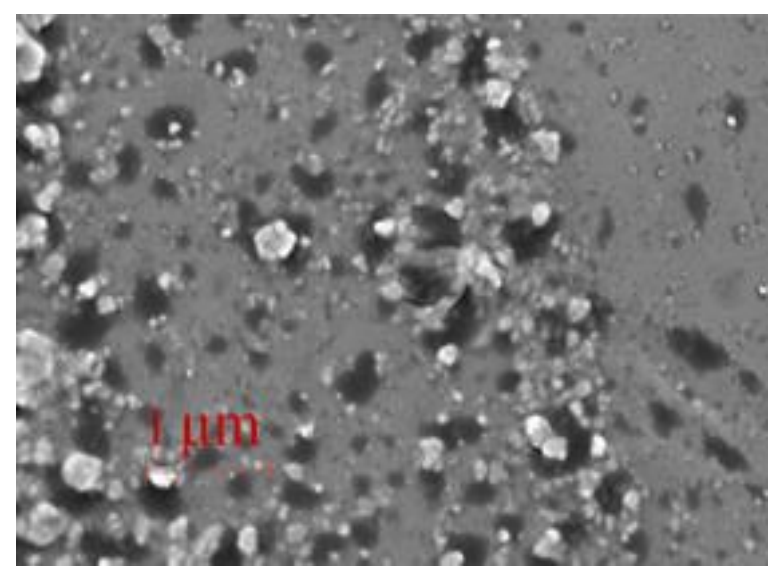




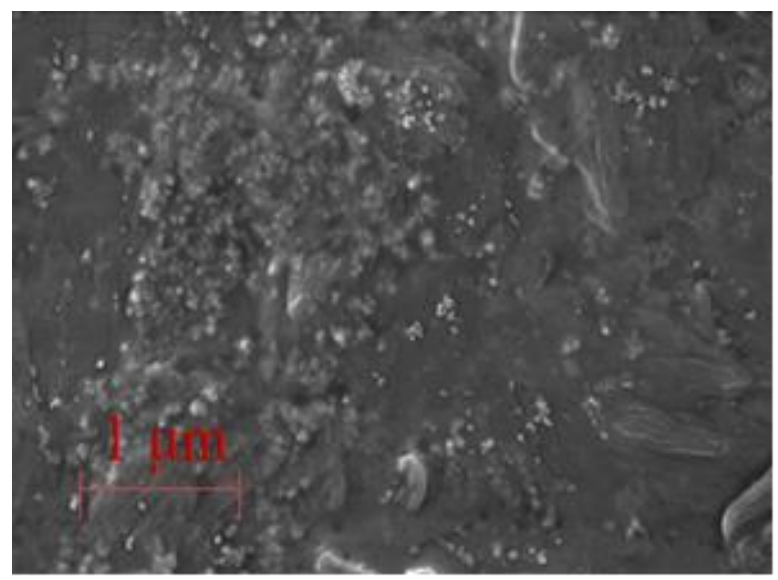

f)

g)

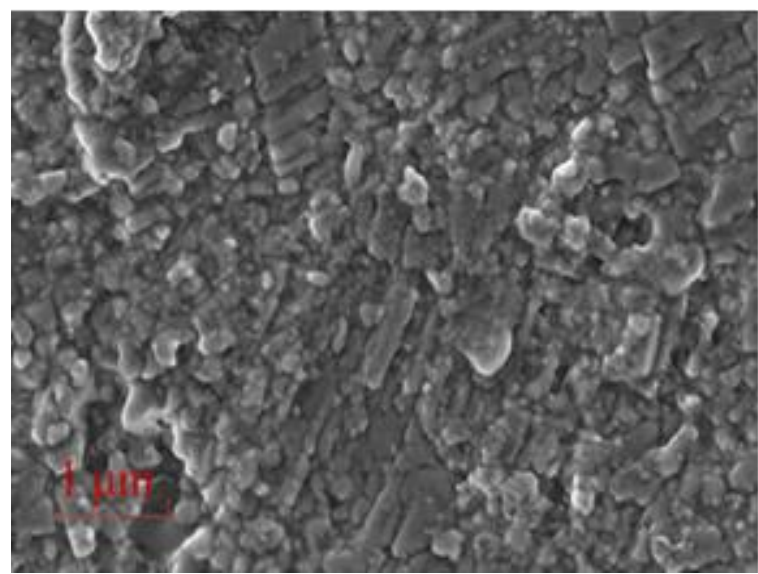

Fig. 2. SEM images of nanoparticle-surfactant modified surfaces: (a) a) Untreated calcite (b) NiO, (c) $\mathrm{ZrO}_{2}$ (d) $\mathrm{NiO} / \mathrm{C}_{16} \mathrm{TAB}$, (e) NiO/TX-100, (f) $\mathrm{ZrO}_{2} / \mathrm{C}_{16} \mathrm{TAB}$ (g) $\mathrm{ZrO}_{2} / \mathrm{TX}-100$.

\subsection{Surface roughness and topography}

Surface roughness and topography are key parameters that influence rock surface wetting. Although contact angle measurement is considered an effective method for evaluating reservoir 
rock wettability, key parameters such as surface roughness and the pore rock structures which impacts liquid-solid contact lines are often not accounted for during the evaluations. For better understanding of the rock surface behaviour, the topography and surface roughness alteration was assessed here using AFM. The AFM [63-65] tests show the topography of the calcite at the nanoscale and the variations in surface roughness for rock surfaces treated with blends of nanoparticle and surfactant and untreated rock. Mean surface roughness $\left(S_{a}\right)$ and root mean square (RMS) roughness was used to ascertain roughness variations.

Table 4. Surface roughness

\begin{tabular}{lll}
\hline Samples & $\mathrm{S}_{\mathrm{a}}(\mathrm{nm})$ & $\mathrm{RMS}(\mathrm{nm})$ \\
\hline & & \\
Untreated & 11 & 16 \\
$\mathrm{NiO} / \mathrm{C}_{16} \mathrm{TAB}$ & 100 & 190 \\
$\mathrm{NiO} / \mathrm{Tx}-100$ & 78 & 180 \\
$\mathrm{ZrO}_{2} / \mathrm{C}_{16} \mathrm{TAB}$ & 120 & 200 \\
$\mathrm{ZrO}_{2} / \mathrm{TX}-100$ & 60 & 83 \\
\hline
\end{tabular}

The untreated calcite (Fig 3a- reference case) had the lowest peak height of $103 \mathrm{~nm}$ (black - 0 $\mathrm{nm}$; white $-103 \mathrm{~nm})$ with a corresponding low roughness average $\left(\mathrm{S}_{\mathrm{a}}-12 \mathrm{~nm}\right)$ and root mean square roughness (RMS-16 nm - Table 4). Different surface roughness variation was observed which impacts wettability as evident via contact angle measurements. The treated calcites showed a significant increase in surface roughness $\left(S_{\mathrm{a}}=20-120 \mathrm{~nm}\right.$ and $\left.\mathrm{RMS}=27-200 \mathrm{~nm}\right)$, as also evident in the SEM images (Fig. 2) and contact angle measurements (Fig. 5-8) as discussed below. TX-100-nanoparticle system (Fig. 3c, e; Table 4) depicts a relatively less rough surface in comparison $\mathrm{C}_{16} \mathrm{TAB}$ (Fig. 3b, d; Table 4). This surface roughness value is an indication of the presence of layer of adsorbed material on the rock surface [63], hence the untreated surface was the smoothest surface. 

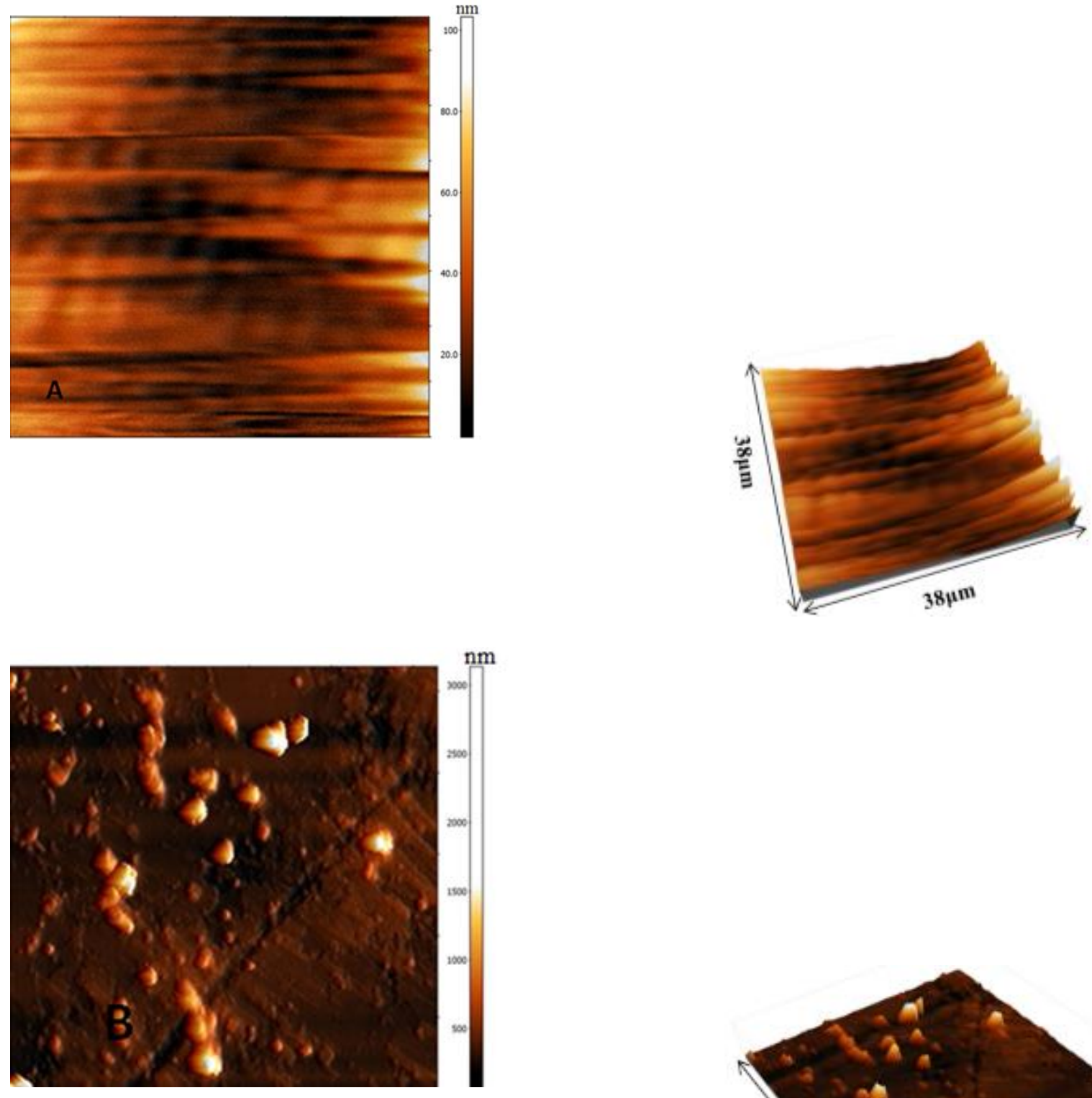

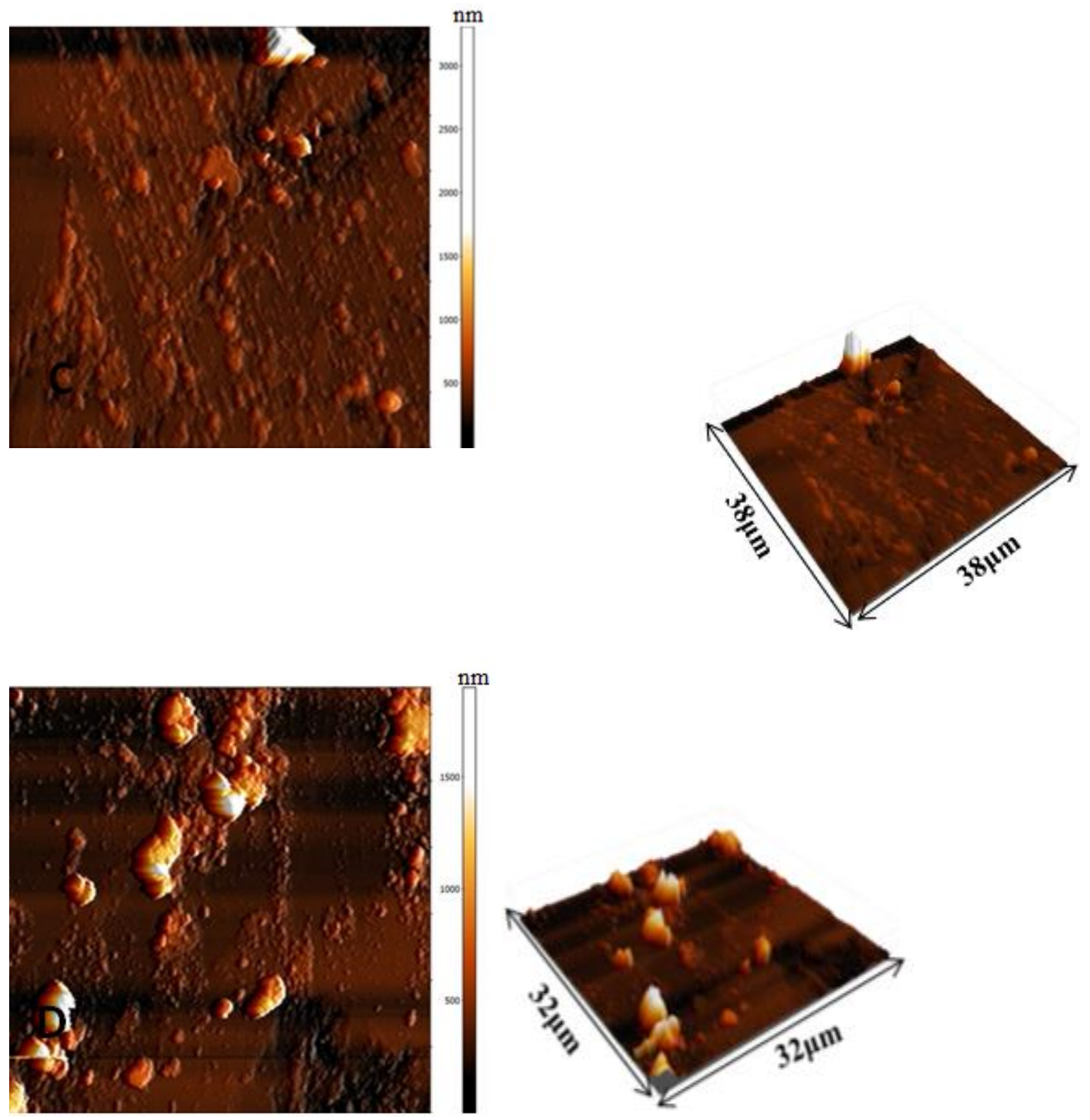

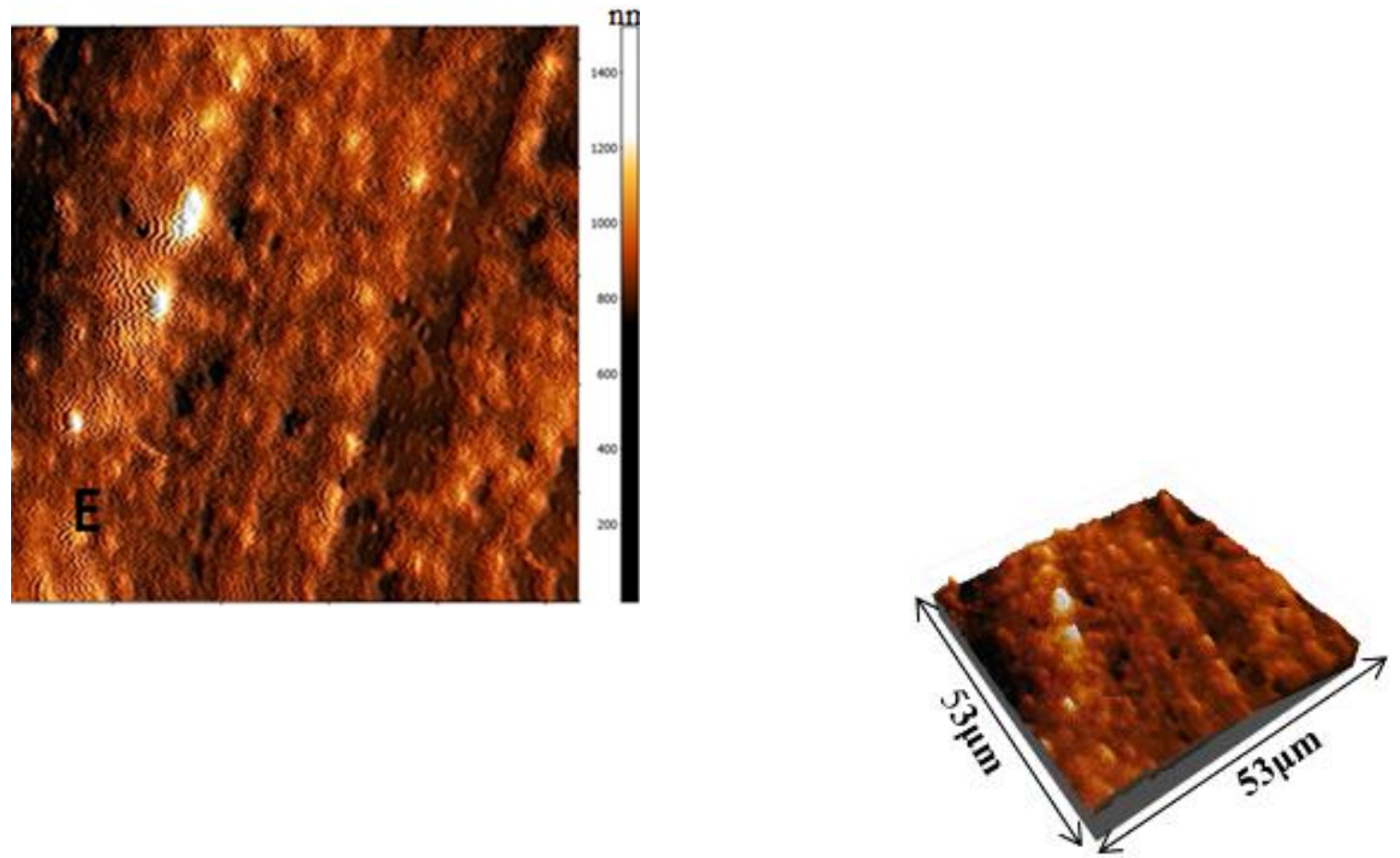

Fig. 3. AFM images of nanoparticle-surfactant modified surfaces: left: top view, right: 3D view. (a) Untreated; treated with: (b) $\mathrm{NiO} / \mathrm{C}_{16} \mathrm{TAB}$ (c) $\mathrm{NiO} / \mathrm{TX}-100$, (d) $\mathrm{ZrO}_{2} / \mathrm{C}_{16} \mathrm{TAB}$ (e) $\mathrm{ZrO}_{2} / \mathrm{TX}-100$. Low peak heights (low Z-values) depict low surface features (dark shades) and high peak heights (high Z-values) show high surface features (lighter shades).

\subsection{Contact angle Measurement}

Contact angle $(\theta)$ measurement is one of the most globally accepted approach for quantifying reservoir wettability. Typically, the $\theta$ is generally not unique as it is dependent on whether the liquid droplet on the surface of the substrate is advancing $\left(\theta_{\mathrm{a}}\right)$ or receding $\left(\theta_{\mathrm{r}}\right)$ [91]. The receding angle $\left(\theta_{\mathrm{r}}\right)$ measurement is achieved via contraction of the liquid drop, thus, considered the angle at the receding edge of the water droplet or the de-wetting angle. Whereas the advancing angle $\left(\theta_{\mathrm{a}}\right)$ measurement is attained via expansion of the liquid drop thus referred to as the angle at the advancing edge of a water droplet or the wetting angle. The water droplet advancing across the substrate surface exceeds the receding as such water advancing $\theta$ is often considered to be of great relevance to reservoir wettability and its imbibing water front. Fig. 9 shows contact angle 
measurements via tilted plate technique. This technique was adopted for measuring advancing and receding angle as it enables measurement of both angles at the same time. However, in complex pore space of rocks, variability in surface roughness and mineralogy also influence the contact angle and thus the rock's wettability $[95,96]$.

A)
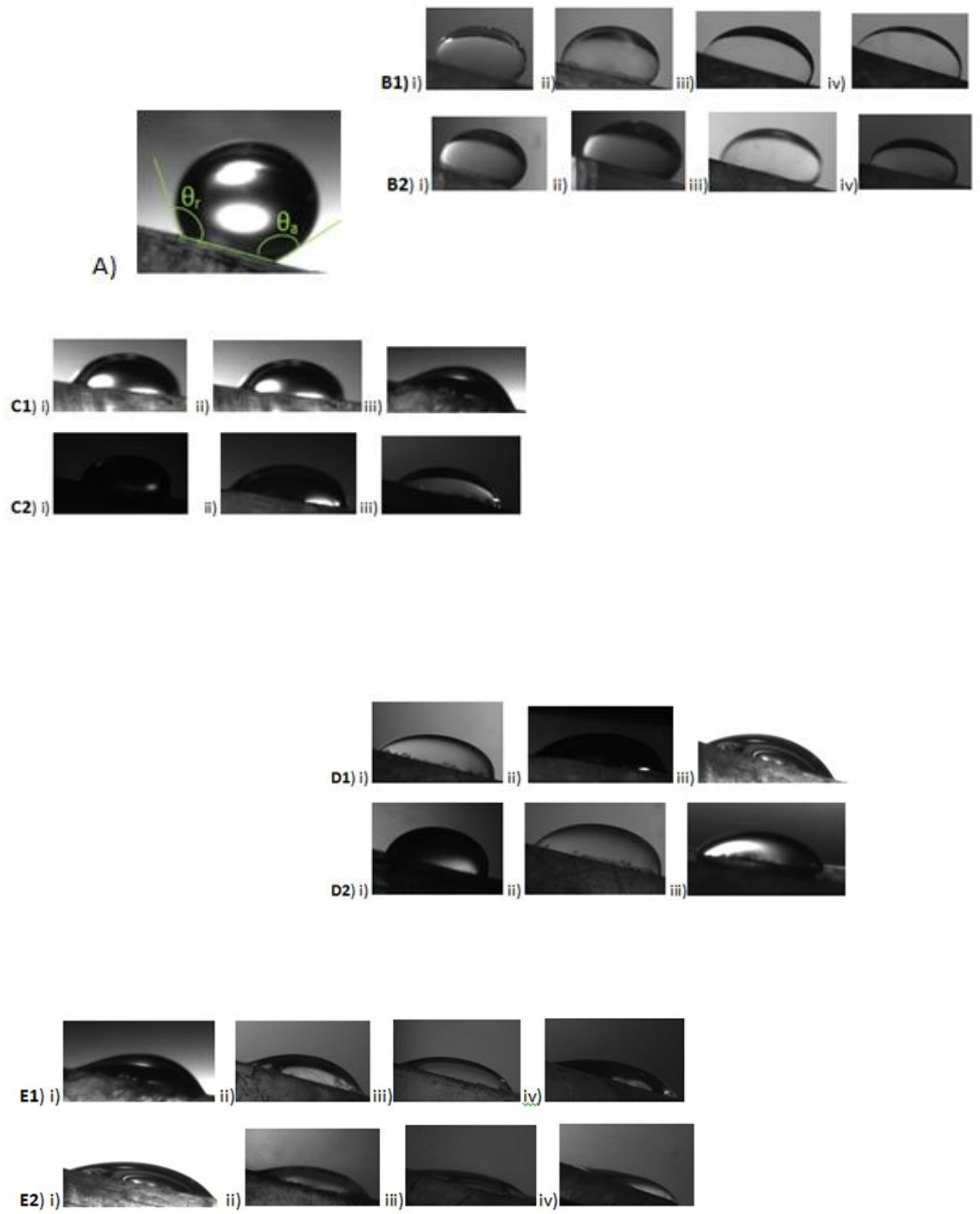

Fig. 9. Image of contact angle $(\theta)$ water droplets on: (A) oil modified rock (high $\theta$ - indicates the surface's hydrophobicity - $152^{\circ} \theta_{\mathrm{a}}$ ); (B) surfactant modified (Exhibiting intermediate wet characteristics I IV);(c)nanoparticle-surfactant modified (C1- NiOC $16 \mathrm{TAB} ; \mathrm{C} 2$ - NiOTX100); (d) nanoparticlesurfactant modified (D1 - $\mathrm{ZrO}_{2} \mathrm{C}_{16} \mathrm{TAB}$; D2 - $\mathrm{ZrO}_{2} \mathrm{TX} 100$ ); (e) and nanoparticle-surfactant modified at different temperature (E1- $\mathrm{ZrO}_{2} \mathrm{TX} 100$; $\mathrm{E} 2-\mathrm{ZrO}_{2} \mathrm{C}_{16} \mathrm{TAB}$ ); (C-E indicates low $\theta$ which represents strong 
interaction with the rock surface thus exhibiting low surface energies and inclination to wet; I - IV); See graphical representation for $\theta$-values.

\subsubsection{Effect of TX-100 and $\mathrm{C}_{16} \mathrm{TAB}$ on wettability}

The potentials of the different surfactants formulations as wetting modifiers were tested on the calcite surface. This serves as a preliminary test to ascertain the wetting efficiency of cetyltrimethylammonium bromide $\left(\mathrm{C}_{16} \mathrm{TAB}\right.$-cationic) and triton $\mathrm{X}-100$ (non-ionic) in the absence of nanoparticles. Contact angle $(\theta)$ measurements were conducted at different surfactant concentrations (0.005 - 0.5 wt. \%). Low concentrations of surfactant were used to avert excessive free surfactants in the bulk. Fig. 4 shows a decrease in $\theta$ with an increase in TX-100 and $\mathrm{C}_{16} \mathrm{TAB}$ concentration and an intermediate wetting attained. The surface property of the oil-wet calcites changed upon exposure to the surfactants creating an adsorbed surface with an increase in surfactant concentration. Although the interaction of the advancing leading edge of the liquid and adsorption on the surface of the solid often leads to a decrease in surfactant concentration near the leading edge [66]. This behaviour can cause an increase in surfactant loss which is typically influenced by the surface chemistry of the rock, surface roughness, type of fluids that the rocks are aged in and how much of the surface is wetted by the fluid, and the thermo-physical treatment conditions. As such, excessive surface adsorption tendencies of surfactants should be avoided to achieve EOR feasibility [36-38]. Overall, $\mathrm{C}_{16} \mathrm{TAB}\left(\theta_{\mathrm{a}}-86^{\circ}\right)$ exhibited better wetting at 0.5 wt. \% than TX-100 $\left(\theta_{\mathrm{a}}-97^{\circ}\right)$. This consistent with reports [15], [27], [50], [67] that cationic surfactants are better wettability modifiers in carbonate reservoirs, which is due to 
favourable adsorption behaviour on the surface of the calcite owing to the electrostatic interaction between the rock surface and the cationic surfactant [15]. The higher wetting efficiency displayed by cationic surfactants can also be attributed to their surface charge, as cationic surfactant bears the same surface charge as carbonate minerals [48].

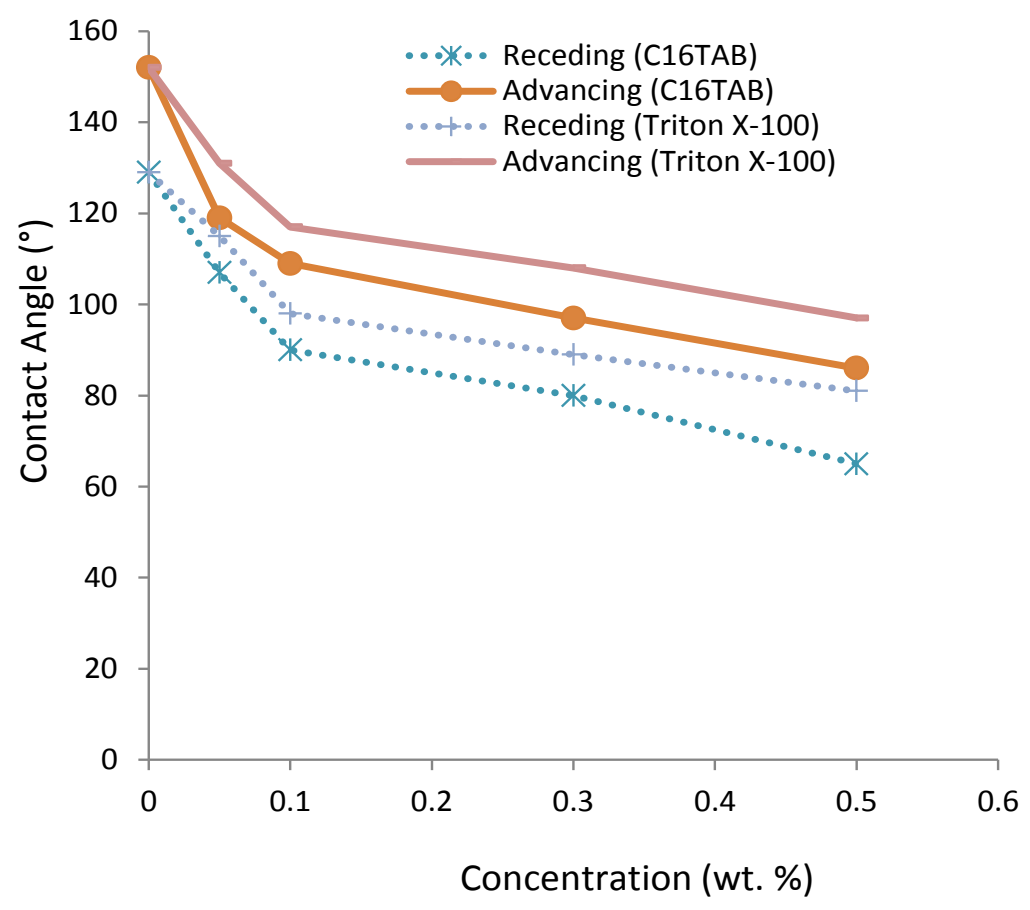

a) 

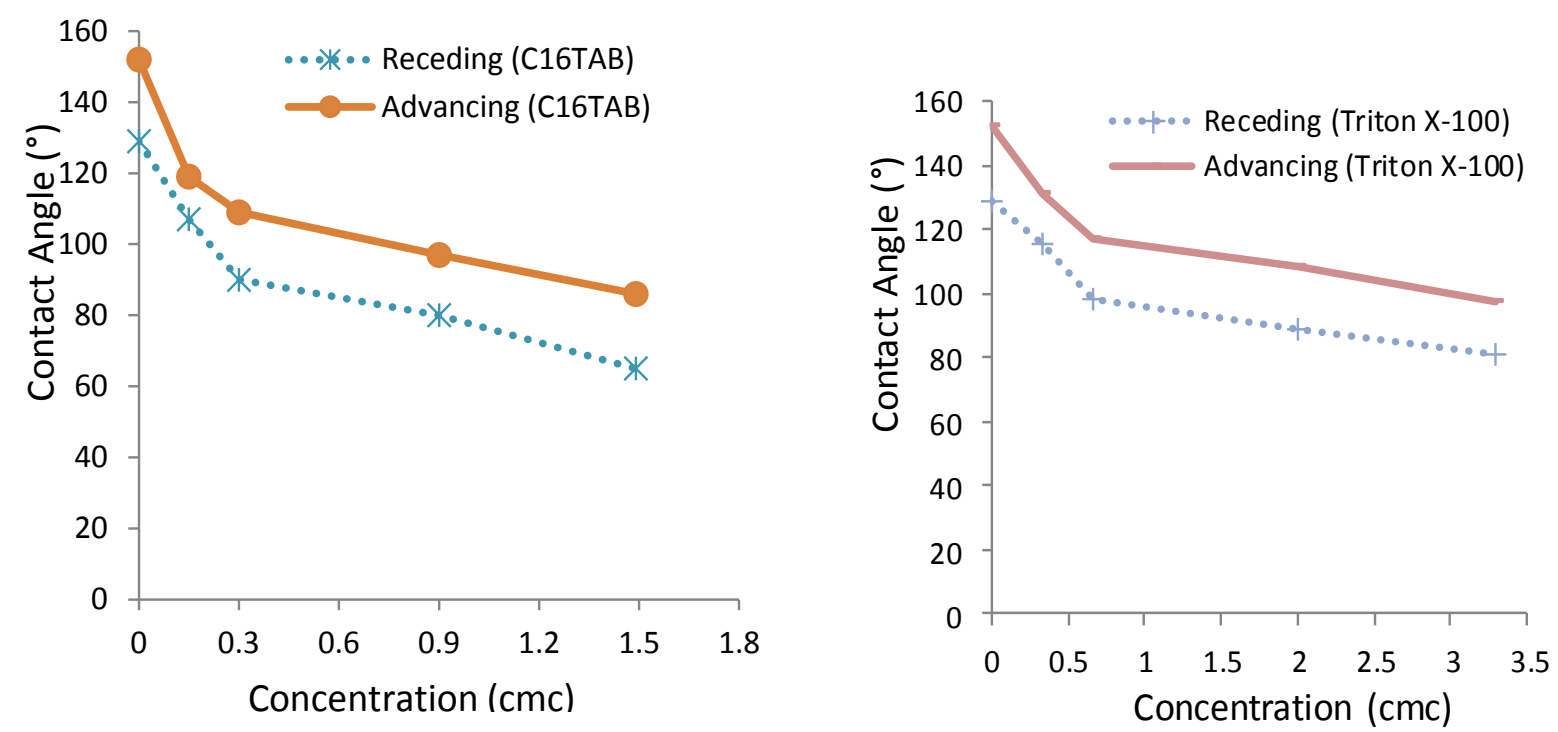

b)

Fig. 4. Water $\theta_{R}$ and $\theta_{A}$ as a function of $C_{16} T A B$ and TX-100 concentration in toluene (1-hour exposure time a) concentration in weight $\%$; b) concentration in $\mathrm{cmc}$ ).

\subsubsection{Effect of nanoparticle on TX-100 and $\mathrm{C}_{16} \mathrm{TAB}$ surfactant performance}

Albeit surfactants have inherent properties as surface active agents, however, the addition of nanoparticles has the potential of enhancing their ability to wet and spread on solid surfaces. To understand the behaviour of nanoparticle-augmented surfactant, the wetting propensity of $\mathrm{C}_{16} \mathrm{TAB}$ and $\mathrm{TX}-100$ surfactants was further tested at ambient temperature $(22 \pm$ $\left.1^{\circ} \mathrm{C}\right)$ in the presence of nanoparticles $\left(\mathrm{ZrO}_{2}\right.$ and $\left.\mathrm{NiO}\right)$ thus changing the property of the wetting fluid. Fig. 5 and 6 show the wetting trends of blends of surfactant (fixed concentration - 0.5 wt. $\%$ - owing to efficiency - Fig. 4) and nanoparticles $\left(\mathrm{ZrO}_{2} / \mathrm{C}_{16} \mathrm{TAB}, \mathrm{ZrO}_{2} / \mathrm{TX}-100, \mathrm{NiO} / \mathrm{C}_{16} \mathrm{TAB}\right.$ and $\mathrm{NiO} / \mathrm{TX}-100$ - concentrations $-0.004-0.05$ wt.\%). The result shows that $\theta$ depend on the nanoparticle-surfactant types, concentration, and indeed the surface roughness of the substrate. $\theta_{\mathrm{a}}$ and $\theta_{\mathrm{r}}$ decreased with increase in nanoparticle concentration in the nanofluid and surface roughness (see AFM - Fig.3). This is in agreement with literature that contact angle is influenced by the fluid-rock interaction and surface roughness of the mineral [58], [63] and [68]. Although 
surfactants are active wettability modifiers [27], [58] and [69] higher magnitude of wettability change was achieved in the presence of nanoparticle.

The presence of the nanoparticles changes the rheological properties of the fluid while increasing the surfactant effect [26]. The particles attach to the rock surface owing to adsorption as evident via SEM (Fig. 2) forming nanostructure layers, as the nanoparticle concentration in the fluid is increased, the surfactants at the surface detaches from the interface and adsorbs on the nanoparticles. The surfactant enhances the physical adsorption on the nanoparticle's surface thus leading to a reduction in surface energy which impedes particle aggregation [70, 54]. Typically, surfactant adsorption on solid surfaces is often dependent on the electrostatic binding, like cationic surfactants onto negatively charged sites of the solid [71]. Such adsorptions are

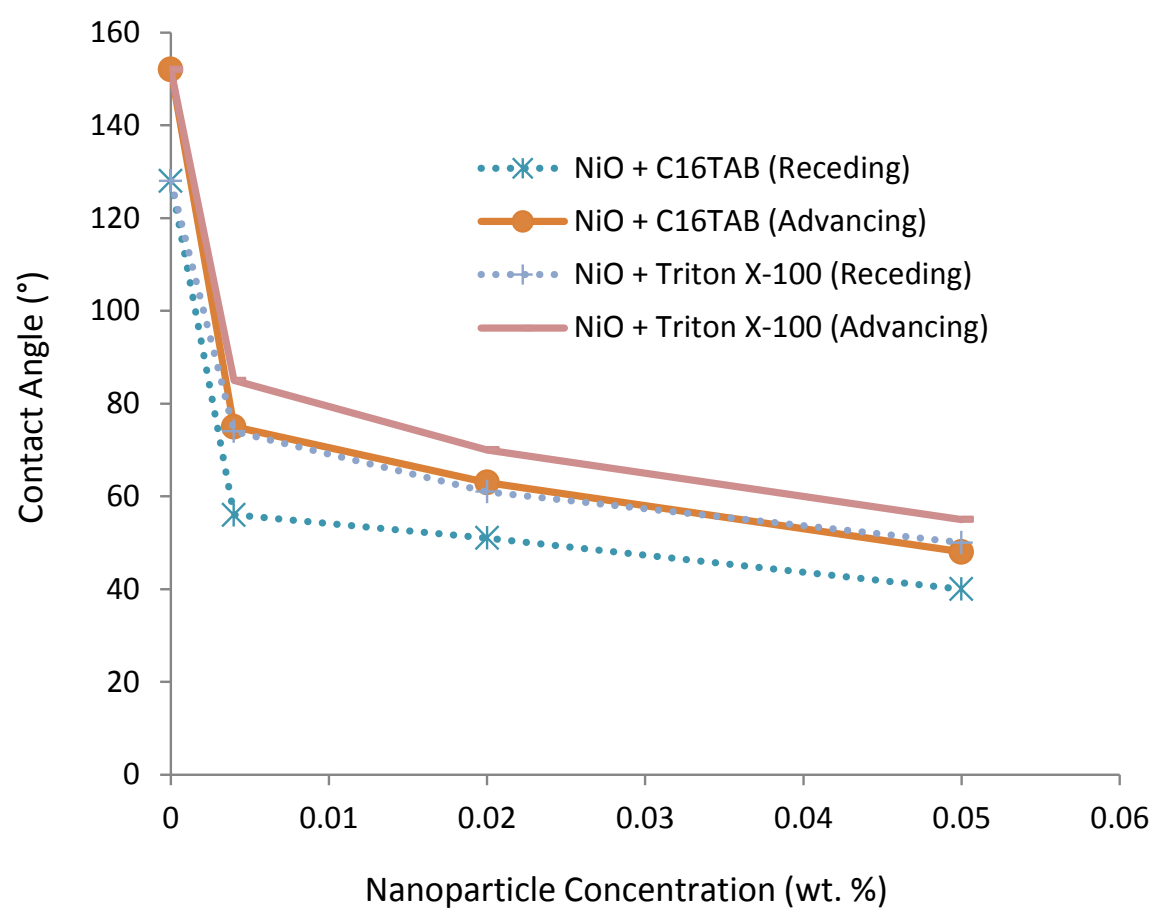

Fig. 5. Wettability alteration efficiency of $\mathrm{NiO}-0.5 \mathrm{wt} . \% \mathrm{C}_{16} \mathrm{TAB}$ and $\mathrm{TX}-100$ in toluene (1-hour Exposure time). 
influenced by the attraction and repulsion force between the surface and the hydrophilic or hydrophobic group and the lateral interactions between the adsorbed surfactants, as previously reported $[72,73]$ which also enhanced $\theta$ decrease towards more water wet conditions. The alteration of formation wettability to preferentially water wet state reduces the forces that binds oil to the rock surface thus causing oil to flow out of the tight formation rock matrix (due to imbibition of water) which facilitate more oil recovery, consistent with literature [62, 74], contrary to micro-emulsions which changes wettability to intermediate wet conditions [88]. Notably, the nanoparticle surfactants system containing TX-100 (non-ionic surfactant) showed better compatibility with $\mathrm{NiO}\left(\mathrm{NiO} / \mathrm{TX}-100-55^{\circ} \theta_{\mathrm{a}}-\right.$ Fig. 5) than $\mathrm{ZrO}_{2}\left(\mathrm{ZrO}_{2} / \mathrm{TX}-100-60^{\circ} \theta_{\mathrm{a}}-\right.$ Fig. 6). However, the $\mathrm{C}_{16} \mathrm{TAB}$-nano blends $\left(\mathrm{ZrO}_{2} / \mathrm{C}_{16} \mathrm{TAB}-35^{\circ}\right.$-Fig. 5 and $\mathrm{NiO} / \mathrm{C}_{16} \mathrm{TAB}-48^{\circ}-$ Fig. 6) consistently decreased $\theta$ than TX-100-nano blend, thus, the $\mathrm{C}_{16} \mathrm{TAB}$ nano-blends were subjected to further testing. 


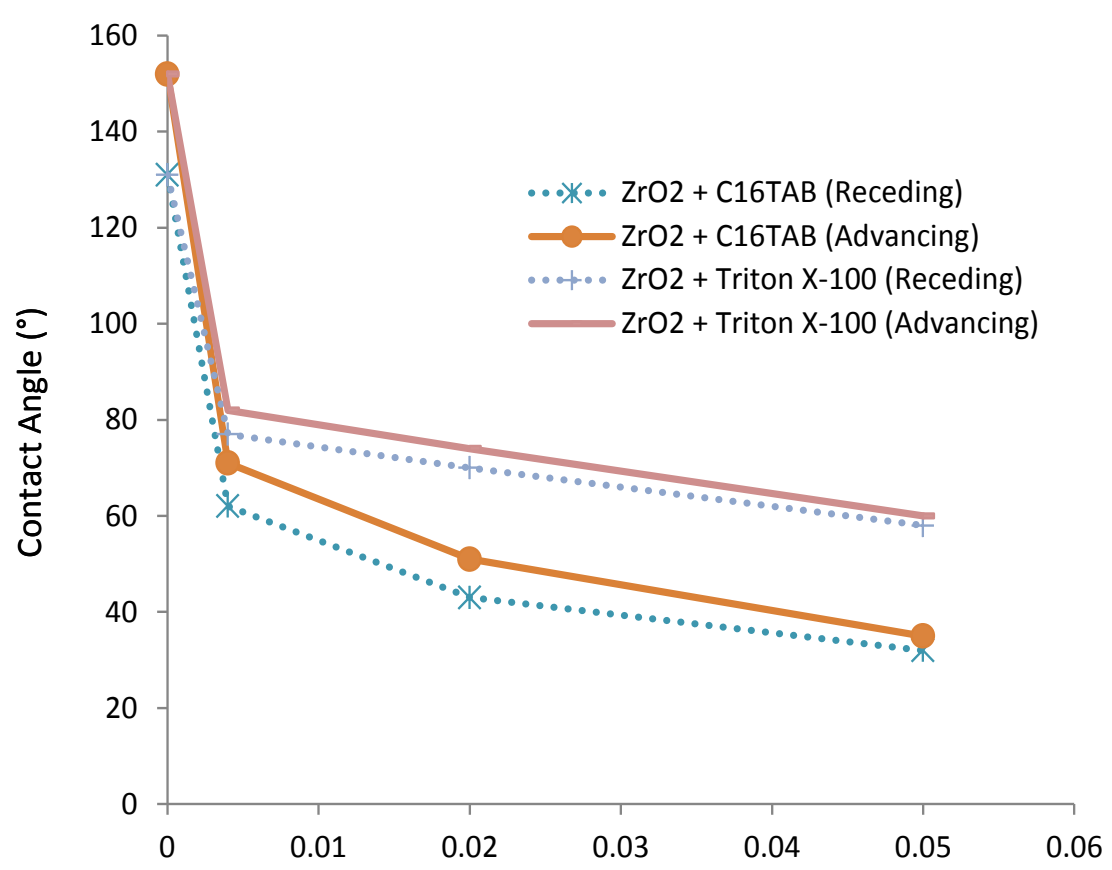

Nanoparticle Concentration (wt. \%)

Fig. 6. Wettability change of $\mathrm{ZrO}_{2}-0.5$ wt.\% $\mathrm{C}_{16} \mathrm{TAB}$ and TX-100 blends in toluene (1-hour Exposure time).

\subsubsection{Effect of temperature on nanoparticle-surfactant performance}

A major challenge with surfactant utilization is temperature sensitivity due to chemical degradation issues. Most surfactant solutions have cloud point temperature (typical range: 30$160^{\circ} \mathrm{C}$ - dependent on surfactant structure), above which the solution becomes cloudy, and can affect the surfactant performance [75]. Alternatively, aqueous nanoparticle dispersions can be used instead of surfactants especially in formations with harsh conditions due to surfactant degradation at high temperature. The presence of nanoparticles which are solids and chemically robust has the potential to stabilize such systems under harsh reservoir conditions [44]. As such the effect of the $\mathrm{C}_{16} \mathrm{TAB}$ nano-blend (0.5 wt. \% surfactant; 0.05 wt. $\% \mathrm{NiO}$ and $\mathrm{ZrO}_{2}$ 
nanoparticles concentrations) was further tested over extensive temperature range $\left(22-70^{\circ} \mathrm{C}\right)$, as colloidal stability of nanoparticles and surfactant under high temperature can pose a great challenge to efficient oil displacements from the porous walls of strongly hydrophobic limestone reservoirs. Clearly, $\theta$ displays high dependency on temperature (Fig. 7), the higher the temperature, the higher the decrease in $\theta_{\mathrm{a}}$ and $\theta_{\mathrm{r}}$. This trend is in good agreement with literature [72], [74] and [76]. The temperature increase decreases $\theta_{\mathrm{a}}$ and $\theta_{\mathrm{r}}$ in the presence of the nanoparticle surfactant systems owing to increase in surface activity as the surface activity of surfactant is enhanced in the presence of nanoparticle. The increase in temperature impacts the oil property leading to a reduction in the oil viscosity, as such, the actively adsorbs nanofluid on the rock surface desorbs the oil thereof, thereby leading to a more water-wet surface especially the $\mathrm{ZrO}_{2} \mathrm{C}_{16} \mathrm{TAB}$ formulations. This is also consistent with Bera et al. [58] and Taborda et al. [77] who reported that oil viscosity reduction enhances oil mobility whilst changing the wettability of the porous medium. Hence, the formulation containing nanoparticles and surfactants enhances emulsion and sedimentation stability via counteracting surface and gravity forces, and formation of swift emulsion [72] as well as wettability alteration of the porous medium or solid surfaces even at elevated temperature with great potentials for upsurging, enhanced oil recovery. This is an indication that the presence of nanoparticle can enhance the surfactant performance and improve the stability of the emulsion [78], this stable behaviour is also similar to microemulsion systems containing surfactant which exhibited great stability with temperature [88]. Thus, nanofluids can be feasible for long-distance migration in the reservoir and have the potential of resolving wettability challenges in limestone formations. 


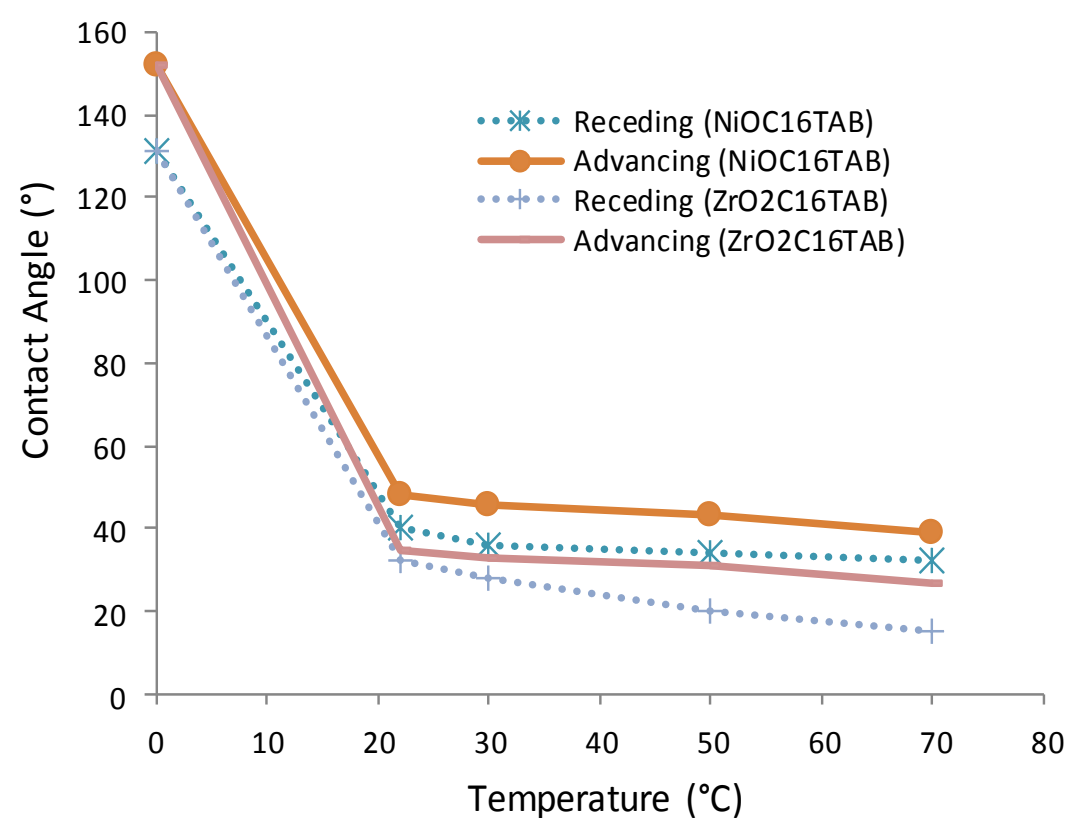

Fig. 7. $\theta_{\mathrm{R}}$ and $\theta_{\mathrm{A}}$ depicting wettability change of $\mathrm{NiO}, \mathrm{ZrO}_{2}(0.05$ wt. $\%) \mathrm{C}_{16} \mathrm{TAB}(0.5$ wt. \%) blends in toluene (1-hour Exposure time) at different temperatures.

\subsection{Spontaneous water imbibition in limestone cores using surfactant-nanoparticles}

Contact angle is a useful wettability evaluation approach, however, the intricate nature of pore space and surfaces of a real reservoir rocks influences the contact angle thus perceived as a limitation. Also, the rock heterogeneity and complex geometry are often not considered as the measurements are usually conducted on a single mineral crystal while ideal cores contain more challenging pores [92]. Thus, the formulated nanoparticle-surfactants was further tested on the potential to enhance water imbibition into the matrix of the limestone rock as the imbibition of a wetting liquid into a porous medium is of great relevance to enhancing reservoir productivity. To avoid repetition, only $\mathrm{C}_{16} \mathrm{TAB}$ (Concentration- 0.5 wt.\%) and the corresponding nano-blends $\left(\mathrm{NiOC}_{16} \mathrm{TAB}, \mathrm{ZrO}_{2} \mathrm{C}_{16} \mathrm{TAB}\right.$ - concentration- $\left.0.05 \mathrm{wt} . \%\right)$ was assessed at different temperature 
(range: $22-70^{\circ} \mathrm{C}$ ) as ascertained via the above contact angle test owing to efficiency. The spontaneous imbibition (SI) test was performed using water as the imbibing fluid. The imbibition test was assessed as a function of time and weight as water imbibes into modified and unmodified core plugs. Comparison of the SI process for core plugs before and after exposure to nanofluids shows similar water imbibing behaviour. The reference test (prior to surfactant-nanomodification) showed the slowest imbibition process, water slowly imbibed into the unmodified limestone core (reference test) before attaining equilibrium at 100mins (Fig. 8). Such slow pace in water penetration into the pores is ascribed to the poor rock wettability, an indication that the surface pore volume is still filled with oil instead of the imbibing liquid (water) as such the pore tends to be less-wetting. The wetting effect of the liquid in contact with the solid surfaces is a key driving force for imbibition. The nanoparticle-surfactant coated (especially $\mathrm{ZrO}_{2} \mathrm{C}_{16} \mathrm{TAB}$ ) cores exhibited better water imbibing tendencies as the water-imbibition rate increased (became quicker) than the cores exposed to surfactant alone, which is also in agreement with the contact angle test above. The fast-spontaneous process led to weight gain by the core thus an indication of a more water-wetting condition, consistent with observation in sandstone cores [59]. This spontaneous imbibition behaviour by the rock is due to capillary action of the interfaces within the pore spaces, the imbibition occurs via a wetting phase front formed by several interfaces acting in consort $[79,80]$. The presence of adsorbed nanoparticles on the porous walls of the rock facilitated the rock wettability change, hence; the water imbibing potential of the limestone rock is enhanced, leading to a faster surface wetting and imbibition, as also reported [81, 82]. Similarly, Zamani et al. [83] reported that surface retention of nanoparticles in porous media is mainly due to adsorption, as such the wettability is preferentially changed towards water wet. 


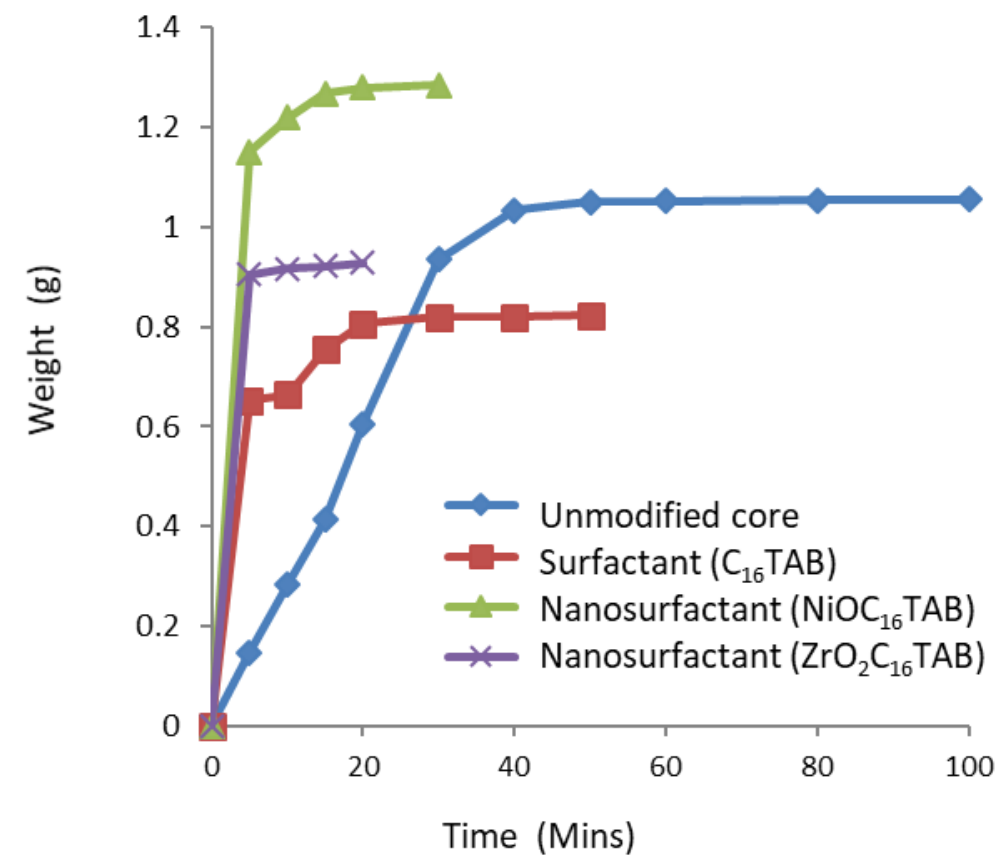

a)

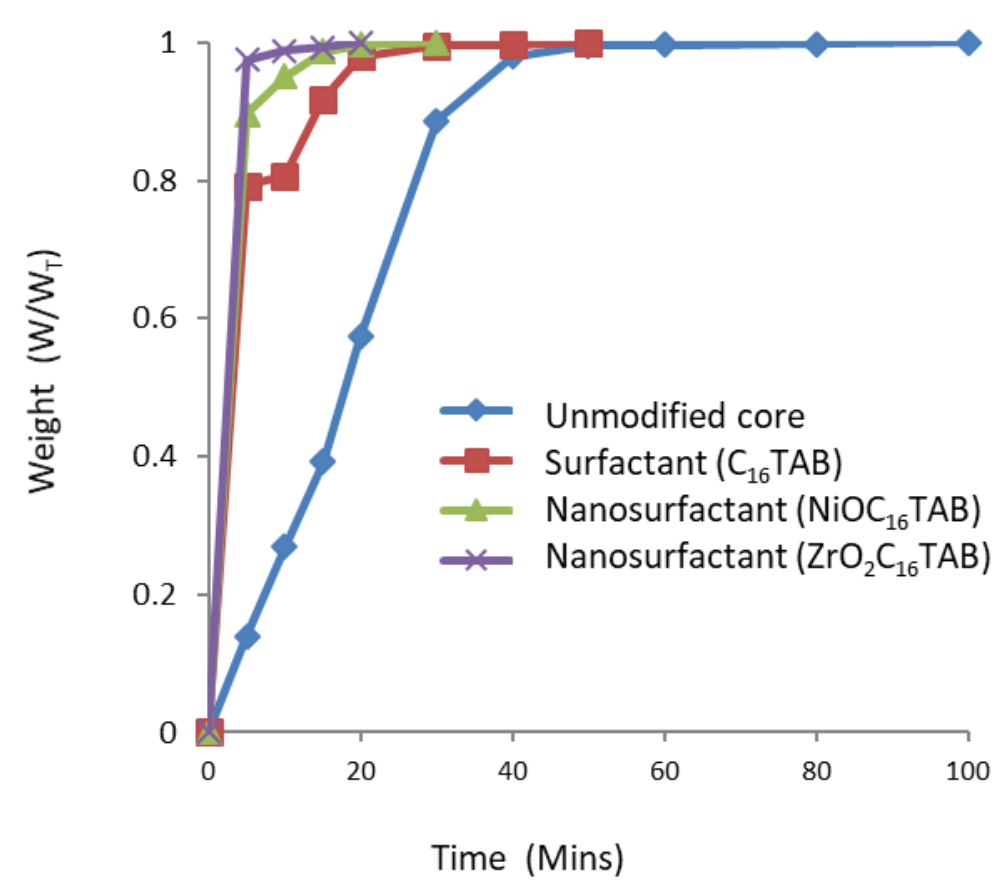

Fig. 8. Spontaneous water imbibition in limestone rock as a function of weight and time: a) actual weight; b) dimensionless weight 
More so, in real porous media with a complex surface coating by asphaltene, the nanoparticle adsorption is enhanced by the spontaneous adsorption of asphaltene on the nanoparticle surface [89]. Such adsorption effects may even further improve recovery as the asphaltene content in a formation can be stabilized [90].

\section{Conclusions}

Wetting of solid by the liquid is an important phenomenon apparent in most applied and industrial processes. However, there is a lack of understanding in terms of the effect of nanofluids on solid surfaces, particularly; the question of whether strongly hydrophobic surfaces can be rendered water-wet is of great relevance in EOR and carbon geo-sequestration as it is well known that productivity from water-wet formations is higher and dramatically lower in oil-wet formations [1], [4-7]. Changing the wetting preference of reservoir rock is an essential approach for facilitating fluid displacement at pore-scale especially in limestone reservoirs which are predominantly oil-wet. Although the use of nanoparticle in combination with surfactant has been previously reported [47], [69] and [84], the focus has mainly been on IFT at the liquid-liquid interface and adsorption. In this study, we have systematically evaluated the wetting propensity of blends of surfactants and nanoparticles on the solid-liquid interface, to ascertain the efficiency of the suspension over wide temperature ranges. New high-performance nanoparticle-surfactant systems were formulated, and the so-called nanoparticle-surfactants (NiO/C $16 \mathrm{TAB}, \mathrm{NiO} / \mathrm{TX}-100$, $\mathrm{ZrO}_{2} / \mathrm{C}_{16} \mathrm{TAB}, \mathrm{ZrO}_{2} / \mathrm{TX}-100$ - nanoparticle-surfactants) showed excellent ability as a new form of EOR agent as the systems clearly enhanced wetting on strongly hydrophobic limestone rock. The presence of nanoparticle had a distinct influence on the behaviour of the surfactants as it 
changes the rheological properties of the fluid while increasing the surfactant effect [26]. It is evident that cationic surfactant $\left(\mathrm{C}_{16} \mathrm{TAB}\right)$ and its nano-blends $\left(\mathrm{ZrO}_{2} / \mathrm{C}_{16} \mathrm{TAB}-\theta=35^{\circ}\right.$ and $\mathrm{NiO} / \mathrm{C}_{16} \mathrm{TAB}-\theta=48^{\circ}$ ) displayed great affinity over non-ionic surfactant $\mathrm{TX}-100$, consistent with reports for carbonate rocks [15], [50], [67] and [85] owing to electrostatic interaction [2]. Albeit, $\mathrm{ZrO}_{2} / \mathrm{C}_{16} \mathrm{TAB}$ demonstrated better efficiency over $\mathrm{NiO} / \mathrm{C}_{16} \mathrm{TAB}$ for all temperatures tested $\left(0-70^{\circ} \mathrm{C}\right)$. A highly hydrophilic state was attained as $\mathrm{ZrO}_{2} / \mathrm{C}_{16} \mathrm{TAB}$ consistently enhanced water-spread on the modified oil-wet rock surface with increasing temperature. $\theta_{\mathrm{a}}$ and $\theta_{\mathrm{r}}$ decreased with increase in nanoparticle concentration in the nanofliud.

Taken into account the morphological evaluation, the adsorption effect of the nanoparticle-surfactants as evident in SEM images (Fig. 2) facilitated the wettability changes towards hydrophilicity as demonstrated via contact angle measurements, consistent with previous reports [27], [37] and [47]. The spontaneous water imbibition test also showed faster water-imbibing tendencies for nanoparticle-surfactant coated cores (especially $\mathrm{ZrO}_{2} / \mathrm{C}_{16} \mathrm{TAB}$ ) than the surfactant coated cores. The wetting trend clearly shows higher wetting propensity was attained in the presence of the complex nanoparticle-surfactant systems. These newly formulated complex systems are novel surface-modifiers than surfactant solution alone with better impact in enhancing formation wettability. The systems are also recommended as a potential stabilizer of dispersed systems, thus ideal for implementation in EOR project design in limestone formation. We thus conclude that wettability alteration can be optimized via usage of nanofluids and hydrocarbon recovery, $\mathrm{CO}_{2}$ geo-storage, and soil de-contamination can be maximized.

\section{References}


[1] N.R. Morrow. Wettability and its effect on oil recovery. J. Pet. Tech. 42 (12), (1990), pp. $1476-1484$.

[2] D. C. Standnes, T. Austad Wettability alteration in carbonates Interaction between cationic surfactant and carboxylates as a key factor in wettability alteration from oil-wet to water-wet conditions. Coll. Surf. A: Physicochem. Eng. Aspects, 216, (2003), pp. 243259.

[3] S. Al-Anssari, A. Barifcani, S. Wang, L. Maxim, S. Iglauer. Wettability alteration of oilwet carbonate by silica nanofluid. J. Coll. and Interf. Sci., 461, (2016), pp. 435-442.

[4] L.N. Nwidee, S. Al-Anssari, A. Barifcani, M. Sarmadivaleh, M. Lebedev, S. Iglauer, 2016. Nanoparticles Influence on Wetting Behaviour of Fractured Limestone Formation. J. Pet. Sci. Eng., 149, (2017), pp. 782-788.

[5] S. Iglauer, A.Z. Al-Yaseri, R. Rezaee, M. Lebedev. $\mathrm{CO}_{2}$-wettability of caprocks: implications for structural storage capacity and containment security. Geophys. Res. Lett., 42 (21), (2015a), pp. 9279-9284.

[6] S. Iglauer, C.H. Pentland, A. Busch. $\mathrm{CO}_{2}$ wettability of storage and seal rock and implications for carbon geo-storage. Water Res. Res., 51 (1), (2015b), pp. 729-774.

[7] E. A. Al-Khdheeawi, S. Vialle, A. Barifcani, M. Sarmadivaleh, S. Iglauer, Impact of reservoir wettability and heterogeneity on $\mathrm{CO}_{2}$-plume migration and trapping capacity, Intern. J. G.H.G Control, (2017), pp. 58, 142.

[8] M. Arif, A. Barifcani, M. Lebedev, S. Iglauer. $\mathrm{CO}_{2}$-wettability of low to high rank coal seams: Implications for carbon sequestration and enhanced methane recovery. Fuel, 181, (2016), pp. 680-689.

[9] D.W. Green, G.P. Willhite. Enhanced Oil Recovery. Henry L. Doherty Memorial Fund of AIME, Society of Petroleum Engineers, Richardson, Texas, (1998); pp. 240-272.

[10] S. Iglauer, Y. Wu, P. Shuler, Y. Tang, W.A. Goddard III. New surfactant classes for enhanced oil recovery and their tertiary oil recovery potential. J. Pet. Sci. Eng., 71 (1-2), (2010b), pp. 23-29. 
[11] S. Iglauer, Y. Wu, P. Shuler, Y. Tang, W.A. Goddard III. Alkyl polyglycoside surfactantalcohol cosolvent formulations for improved oil recovery. Coll. Surf. A: Physicochem. Eng. Aspects, 339, (2009), pp. 48-59.

[12] S. Iglauer, Y. Wu, P. Shuler, M. Blanco, Y. Tang, W.A. Goddard III. Alkyl polyglycoside Surfactants for improved oil recovery. SPE/DOE 2004, http://dx.doi.org/10.2118/89472-MS.

[13] H.L. Chen, L.R. Lucas, L.A.D. Nogaret, H.D. Yang, D.E. Kenyon. Laboratory monitoring of surfactant imbibition with computerized tomography. SPE Reserv. Eval. Eng., 4 (1), (2001), pp. 16-25.

[14] E. Golabi, F. Seyedeyn-Azad, S. Ayatollahi. Chemical induced wettability alter-ation of carbonate reservoir rocks. Iran. J. Chem. Eng., 6, (2009), pp. 67.

[15] T. Austad, B. Matre, J. Milter, A. Saevareid, L. Oyno. Chemical flooding of oilreservoirs 8 - spontaneous oil expulsion from oil-wet and water-wet low permeable chalk material by imbibition of aqueous surfactant solutions. Colloids Surf. A: Physicochem. Eng. Aspects, 137, (1998), pp. 117-129.

[16] P. Kathel, K.K. Mohanty. Wettability alteration in a tight oil reservoir. Energy Fuels, 27, (2013), pp. 6460-6468.

[17] R. G. Dos Santos, R.S. Mohamed, A.C. Bannwart, W. Loh. Contact angle measurements and wetting behavior of inner surfaces of pipelines exposed to heavy crude oil and water. J. Pet. Sci. Eng. 51, (2006), pp. 9-16.

[19] T. Ahmadall, M.V. Gonzalez, J. H. Harwell, J. F. Scamehorn. Reducing surfactant adsorption in carbonate reservoirs. SPE Reserv. Eval. Eng., 8, (1993), pp. 117-122.

[20] K.H. Jarrahiana, 1.O. Seiedi, M. Sheykhan, M.V. Sefti, S. H. Ayatollahi. Wettability alteration of carbonate rocks by surfactants: A mechanistic study. Colloids and Surfaces A: Physicochem. Eng. Aspects, 410, (2012), pp. 1- 10.

[21]B. Hou, Y. Wang, Y. Huang. Mechanistic study of wettability alteration of oil-wet sandstone surface using different surfactants. Appl. Surf. Sci., 330, (2015), pp. 56-64. 
[22] A. Bera, T. Kumar, K. Ojha, A. Mandal. Adsorption of surfactants on sand surface in enhanced oil recovery: Isotherms, kinetics and thermodynamic studies. App. Surf. Sci., 284 (2013), pp. 87-99.

[23] A. Bera, K. Ojha, T. Kumar, A. Mandal. Water solubilization capacity, interfacial compositions and thermodynamic parameters of anionic and cationic microemulsions. Colloids and Surfaces A: Physicochem. Eng. Aspects, 404 (2012), pp. 70- 77

[24] L.L. Schramm. Surfactants: fundamentals and applications in the petroleum industry. Cambridge University Press: United Kingdom, (2000), pp 121-203.

[25] T. Babadagli. Scaling of cocurrent and counter current capillary imbibition for surfactant and polymer injection in naturally fractured reservoir. SPE J., 6(4), (2001), pp. 465-478.

[26] G. Hirasaki, D.L. Zhang. Surface chemistry of oil recovery from fractured oil-wet carbonate formations. SPE J., 9(2), (2004), pp. 151-162.

[27] D.L. Zhang, S.H. Liu, M. Puerto, C.A. Miller, G.J. Hirasaki. Wettability alteration and spontaneous imbibition in oil-wet carbonate formations. J. Pet. Sci. Eng., 52, (2006), pp. 213-226.

[28] Y. Wu, P. Shuler, M. Blanco, Y. Tang, W.A. Goddard. An experimental study of wetting behavior and surfactant EOR in carbonates with model compounds. SPE J., 13 (01), (2008), pp. 26-34.

[29]Z. Bi, W. Liao, L. Qi. Wettability alteration by CTAB adsorption at surface of $\mathrm{SiO} 2$ film or silica gel powder and mimic oil recovery. Appl. Surf. Sci., 221, (2004), pp. 25-31.

[30] R. Zhang, P. Somasundaran. Advances in Adsorption of Surfactant and their Mixtures at Solid/Solution interfaces. Adv. Colloid Interface Sci., 123-126, (2006), pp. 213-229.

[31] M. J. Rosen. Surfactants and Interfacial Phenomena. John Wiley \& Sons: Hoboken, New Jersey, (2004), pp 105-198.

[32] M. Skočibušić, R. Odžak, I. Štefanić, L. KrižićKrišto, O. Jović, T. Hrenar, I. Primožič, D. Jurašin. Structure-property relationship of quinuclidinium surfactants-towards 
multifunctional biologically active molecules. Coll. Surf. B: Biointerfaces, 140, (2016), pp. 548 .

[33]Z. Zhou, Q. Zhang, H. Wang, Xu, L. Zhang, D. Liu, L. Zhang. Wettability of a PTFE surface by aqueous solutions of zwitterionic surfactants: Effect of molecular structure. Coll. Surf. A: Physicochem. Eng. Aspects, 489, (2016), pp. 370-377.

[34] F.D.S. Curbelo, V.C. Sntanna, E.L. Barros Neto, T.V. Dutra, T.N.Castro Dantas, A.A. Dantas Netro, A.I.C. Garnica. Adsorption of nonionic surfactants in sandstones. Colloid Surf. A, 293, (2007), pp. 1-4.

[35] Y. Wu, S. Iglauer, P. Shuler, Y. Tang, W.A. Goddard III. Experimental study of surfactant retention on kaolinite clay. Tenside Surfactants Detergents, 48 (5), (2011), pp. 346-358.

[36] L.N. Nwidee, S. Theophilus, A. Barifcani, M. Sarmadivaleh, S. Iglauer. EOR processes, opportunities and technological advancements, chemical enhanced oil recovery (cEOR) a Practical Overview, InTech., (2016), pp. 1-52.

[37] M. Zargartalebi, R. Kharrat, N. Barati. Enhancement of surfactant flooding performance by the use of silica Nanoparticles. Fuel., 143, (2015), pp. 21-27.

[38] A. Bera, K. Ojha, A. Mandal, T. Kumar. Interfacial tension and phase behavior of surfactant-brine-oil system. Colloids and Surfaces A: Physicochem. Eng. Aspects, 383 (2011), pp. 114-119.

[39] S.K. Das, S.U.S. Choi, H.E. Patel, Heat Transfer in Nanofluids - a review, Heat Transfer Eng. 27 (10) (2006), pp. 3-19.

[40] L.N. Nwidee, S. Al-Anssari, A. Barifcani, M. Sarmadivaleh, S. Iglauer. Nanofluids for Enhanced Oil Recovery Processes: Wettability Alteration Using Zirconium Oxide. OTC 2016.

[41]W. Yu, H. Xie. A Review on Nanofluids: Preparation, Stability mechanisms and Applications. J. Nanomater, (2012), pp. 1-17. 
[42] T. Sharma, G.S. Kumar, J. S.Sangwai. Comparative effectiveness of production performance of Pickering emulsion stabilized by nanoparticle-surfactant-polymer over surfactant-polymer (SP) flooding for enhanced oil recovery for Brownfield reservoir. Journal Pet. Sci. Eng., 129 (2015), pp. 221-232.

[43] T. Sharma, G.S. Kumar, B.H Chon, J.S. Sangwai. Thermal stability of oil-in-water Pickering emulsion in the presence of nanoparticle, surfactant, and polymer. J. Indust. Eng. Chem. 22 (2015), pp. 324-334.

[44] S.J. Jikich. $\mathrm{CO}_{2}$ EOR: Nanotechnology for mobility control studied. JPT (2012), 28-31.

[45] M.A. Ahmadi, S.R Shadizadeh. Induced effect of adding nano silica on adsorption of a natural surfactant onto sandstone rock: Experimental and theoretical study. J. Pet. Sci. a Eng., 112 (2013), 239-247.

[46] Q. Lan, F. Yang, S. Zhang, S. Liu, J. Xu, D. Sun. Synergistic effect of silica nanoparticle and cetyltrimethyl ammonium bromide on the stabilization of $\mathrm{O} / \mathrm{W}$ emulsions, Colloids and Surfaces A: Physicochem. Eng. Aspects, 302 (2007), pp. 126-135.

[47]P. Esmaeilzadeh, N. Hosseinpour, A. Bahramian, Z. Fakhroueian, S. Arya. Effect of $\mathrm{ZrO}_{2}$ nanoparticles on the interfacial behavior of surfactant solutions at air-water and nheptane-water interfaces. Fluid Phase Equilibria, 361 (2014), pp. 289-295.

[48] A. Seethepalli, B. Adibhatla, K.K. Mohanty. Physicochemical interactions during surfactant flooding of fractured carbonate reservoirs. SPE J. 9 (2004), pp. 411-418.

[49] D.C. Standnes, T. Austad. Wettability Alteration in Chalk 1. Preparation of Core Material and Oil Properties, J. Pet. Sci. Eng. (2000), pp. 28, 111.

[50]D.C. Standnes, T. Austad. Wettability Alteration in Chalk 2. Mechanism for Wettability Alteration from Oil-Wet to Water-Wet Using Surfactants, J. Pet. Sci. Eng. (2000), pp. 28, 123.

[51]D.C. Standnes, T. Austad. Wettability alteration in carbonates: Interaction between cationic-surfactant and carboxylates as a key factor in wettability alteration from oil-wet 
to water-wet conditions, Colloids and Surfaces A: Physicochem. Eng. Aspects (2003), pp. 216, 243.

[52] D.C. Standnes, L.A.D. Nogaret, H.L. Chen, T. Austad. An evaluation of spontaneous imbibition of water into oil-wet carbonates reservoir cores using anonionic and a cationic surfactant. Energy Fuels. 16, (2002), pp. 1557-1564.

[53] M.A. Ahmadi, M. Galedarzadeh, S. R. Shadizadeh. Wettability alteration in carbonate rocks by implementing new derived natural surfactant: enhanced oil recovery applications. Transport Porous Med., 106, (2015), pp. 645-667.

[54] F. Guo, S. Aryana, An experimental investigation of nanoparticle-stabilized CO2foam used in enhanced oil recovery. Fuel, 186, (2016), pp. 430-442.

[55] W.G. Anderson. Wettability literature survey - part 1: rock/oil/brine interactions and the effects of core handling on wettability. J.Pet.Tech. 38 (10), (1986a), pp. 1125-1144.

[56] S. Iglauer, T. Rahman, M. Sarmadivaleh, A. Al-Hinai, M. Ferno, M. Lebedev. Influence of wettability on residual gas trapping and enhanced oil recovery in three-phase flow: a pore-scale analysis using micro-computed tomography. SPE J., (2016), pp.1 -14.

[57] T. Rahman, M. Lebedev, A. Barifcani, S. Iglauer. Residual trapping of supercritical $\mathrm{CO}_{2}$ in oil-wet sandstone. J. Coll. Interf. Sci., 469, (2016), pp. 63-68.

[58] A. Bera, S. Kissmathulla, K. Ojha, T. Kumar, A. Mandal. Mechanistic study of wettability alteration of quartz surface induced by nonionic surfactants and interaction between crude oil and quartz in the Presence of Sodium Chloride Salt. Energy Fuels, 26, (2012), pp. 3634-3643.

[59] J. Giraldo, P. Benjumea, S. Lopera, F.B. Cortés, M.A. Ruiz. Wettability Alteration of Sandstone Cores by Alumina-Based Nanofluids. Energy and Fuels. 27, (2013), pp. 36593665 .

[60] K. Winkler, M. Paszewski, T. Kalwarczyk, E. Kalwarczyk, T. Wojciechowski, E. Gorecka, D. Pociecha, R. Holyst, M. Fialkowski, M. Ionic strength-controlled deposition 
of charged nanoparticles on a solid substrate. J. Phys. Chem., 115 (39), (2011), pp. 19096-19103.

[61] A. Nikolov, K. Kondiparty, D. Wasan. Nanoparticle self-structuring in a nanofluid film spreading on a solid surface. Langmuir, 26 (11), (2010), pp. 7665-7670.

[62] M. Ershadia, M. Alaeib, A. Rashidib, A. Ramazania, S. Khosravania. Carbonate and sandstone reservoirs wettability improvement without using surfactants for Chemical Enhanced Oil Recovery (C-EOR). Fuel, 153, (2015), pp. 408-415.

[63] J.S. Buckley, D.L. Lord. Wettability and morphology of mica surfaces after exposure to crude oil. J. Pet. Sci. Eng. 39, (2003), pp. 261-273.

[64] K. Jarrahian, O. Seiedi, M. Sheykhan, M.V. Sefti, S. Ayatollahi. Wettability alteration of carbonate rocks by surfactants: a mechanistic study. Colloids Surf. A: Physicochem. Eng. Asp. 410, (2012), pp. 1-10

[65] S. Zargari, S. Ostvar, A., Niazi, S. Ayatollahi. Atomic force microscopy andwettability study of the alteration of mica and sandstone by a biosurfactantproducing bacterium bacillus thermodenitrificans. J. Adv. Microsc. Res., 5, (2010), pp. 143-148.

[66] K.P. Ananthapadmanabhan, E.D. Goddard, P. Chandar. A study of the solution, interfacial and wetting properties of silicone surfactants. Colloids Surf., 44 (1990), pp. 281-297.

[67] J. Sheng, Modern chemical enhanced oil recovery: theory and practice. Elsevier Publication Inc: Amsterdam, (2011), pp. 239-334.

[68] A. Z. Al-Yaseri, M. Lebedev, A. Barifcani, S. Iglauer. Receding and advancing $\left(\mathrm{CO}_{2}+\right.$ brine + quartz) contact angles as a function of pressure, temperature, surface roughness, salt type and salinity. J. Chem. Thermo., 93, (2016), pp. 416-423.

[69] S. C. Ayirala, S. C. Vijapurapu, D. N. Rao. Beneficial effects of wettability altering surfactants in oil-wet fractured reservoirs S.C. Journal of Petroleum Science and Engineering 52, (2006), pp. 261-274. 
[70]F. Ravera, E. Santini, G. Loglio, M. Ferrari, L. Liggieri, Effect of nanoparticles on the interfacial properties of liquid/liquid and liquid/air surface layers, J. Phys. Chem. B., 110 (2006), pp. 19543-19551.

[71] Y. Chevalier, M. Bolzinger. Emulsions stabilized with solid nanoparticles: Pickering emulsions. Colloids and Surfaces A: Physicochem. Eng. Aspects 439 (2013), pp. $23-34$.

[72] M.A. Muherei, R. Junin. Equilibrium Adsorption Isotherms of Anionic, Nonionic Surfactants and Their Mixtures to Shale and Sandstone. Modern Applied Science, 3(2), (2009), pp. 158-167.

[73] M.A. Ahmadi, S. R. Shadizadeh. Induced effect of adding nano silica on adsorption of a natural surfactant onto sandstone rock: Experimental and theoretical study. J. Pet. Sci. Eng. 112 (2013), pp. 239-247.

[74] A.N. El-hoshoudy, S.E.M. Desouky, M.A. Betiha, A.M. Alsabagh. Use of 1-vinyl imidazole based surfmers for preparation of polyacrylamide- $\mathrm{SiO}_{2}$ nanocomposite through aza-Michael addition copolymerization reaction for rock wettability alteration. Fuel, 170, (2016), pp. 161-175.

[75]C. Negin, S. Ali, Q. Xie, Most common surfactants employed in chemical enhanced oil recovery, Petroleum (2017) in press, doi: 10.1016/j.petlm.2016.11.007.

[76] A.A. Hamouda, O. Karoussi. Effect of temperature, wettability and relative permeability on oil recovery from oil-wet chalk. Energies, 1, (2008), pp. 19-34.

[77] E.A. Taborda, C.A. Franco, S.H. Lopera, V. Alvarado, F.B. Cortés. Effect of nanoparticles/nanofluids on the rheology of heavy crude oil and its mobility on porous media at reservoir conditions. Fuel, 184, (2016), pp. 222-232.

[78] M. Mohajeri, M. Hemmati, A.S. Shekarabi. An experimental study on using a nanosurfactant in an EOR process of heavy oil in a fractured micromodel. J. Pet. Sci. Eng., 126, (2015), pp. 162-173. 
[79] G. Liu, Z. Lu, M. Zhang, C. Ridgway, P. Gane. Structural evidence for the timescale separated liquid imbibition phenomenon in porous media. Powder Tech., 310 (2017), pp. $8-16$.

[80] G. Mason, N.R. Morrow. Developments in spontaneous imbibition and possibilities for future work. J. Pet. Sci. Eng., 110, (2013), pp. 268-293.

[81] A. Maghzi, S. Mohammadi, M.H.Ghazanfari, R. Kharrat, M. Masihi. Monitoring wettability alteration by silica nanoparticles during water flooding to heavy oils in fivespot systems: a pore-level investigation. Exp. Therm. Fluid. Sci., 40, (2012), pp. 168-76.

[82] B. Ju, T. Fan. Experimental study and mathematical model of nanoparticle transport in porous media. Powder Technol., 192, (2009), pp. 195-202.

[83] A. Zamani, B. Maini, P. Pereira-Almao. Experimental study on transport of ultradispersed catalyst particles in porous media. Energy Fuels, 24, (2010), pp. 4980-8.

[84] H. Ma, M. Luo, L.L. Dai, Influences of surfactant and nanoparticle assembly on effective interfacial tensions, Phys. Chem. Chem. Phys 10, (2008), pp. 2207-2213.

[85] H. ShamsiJazeyi, M.A. Clarence, W.S. Michael, M.T. James, R. Verduzco. Polymercoated nanoparticles for enhanced oil recovery. J. Appl. Polym. Sci., 40576, (2014), pp. $1-13$.

[86] N. Alyafei, M. J. Blunt. The effect of wettability on capillary trapping in carbonates. Advances in Water Resources, (2016), pp. 36-50.

[87] B.A. Kvanvik, A. Skauge, B. Matre, K. Kolltveit. Three-phase microemulsion relative permeabilities: Experimental and theoretical consideration J.Petrol. Sci. Eng., 7, (1992), pp. 105-116.

[88] A. Hussain, P. F. Luckham, T. F. Tadros. Phase behavior of ph dependent microemulsions at high temperatures and high salinity. Oil Gas Sci Technol Rev IFP, 52, (1997), pp. 228-231. 
[89] N.N. Nassar. Asphaltene Adsorption onto Alumina Nanoparticles: Kinetics and Thermodynamic Studies. Energy Fuels, 24, (2010), pp. 4116-4122.

[90] C.A. Franco, N.N. Nassar, M.A. Ruiz, P. Pereira-Almao, F.B. Cortes. Nanoparticles for Inhibition of Asphaltenes Damage: Adsorption Study and Displacement Test on Porous Media. Energy Fuels, 27, (2013), pp. 2899-2907.

[91] S. Hong, T. Chou, Y. Liu, Y. Sheng, H. Tsao. Advancing and receding wetting behavior of a droplet on a narrow rectangular plane. Colloid Polym Sci., 291 (2013), pp. 347-353.

[92] W.G. Anderson. Wettability Literature Survey Part 2: Wettability Measurement. JPT (1986) pp.1246-1262.

[93] O. Falode, E. Manuel. Wettability Effects on Capillary Pressure, Relative Permeability, and Irredcucible Saturation Using Porous Plate. J. Petrol Eng., 2014, 465418, pp. 12

[94] P. C. Reeves, M. A. Celia. A functional relationship between capillary pressure, saturation, and interfacial area as revealed by a pore-scale network model. Water Resources Research, 32 (1996), 8, pp. 2345-2358.

[95] A. Scanziani, K. Singh, M. J. Blunt, A. Guadagnini. Automatic method for estimation of in situ effective contact angle from X-ray micro tomography images of two-phase flow in porous media. J. Coll. Interf. Sci., 496, (2017), pp. 51-59.

[96] Iglauer, S. (2017). " $\mathrm{CO}_{2}$-water-rock wettability: variability, influencing factors, and implications for $\mathrm{CO}_{2}$ geostorage." Accounts of Chemical Research, 50(5), 1134-1142. 